\title{
Callbration of
}

\section{Secondary Standard}

\section{Magnetic Tape Cassettes}

$-Q C$ 100 45753 no. 731 1972

U.S. PARTMENT OF OMMERCE National Bureau of Standards

\section{(Computer Amplitude Reference)}

Phase I 
The National Bureau of Standards ${ }^{1}$ was established by an act of Congress March 3, 1901. The Bureau's overall goal is to strengthen and advance the Nation's science and technology and facilitate their effective application for public benefit. To this end, the Bureau conducts research and provides: (1) a basis for the Nation's physical measurement system, (2) scientific and technological services for industry and government, (3) a technical basis for equity in trade, and (4) technical services to promote public safety. The Bureau consists of the Institute for Basic Standards, the Institute for Materials Research, the Institute for Applied Technology, the Center for Computer Sciences and Technology, and the Office for Information Programs.

THE INSTITUTE FOR BASIC STANDARDS provides the central basis within the United States of a complete and consistent system of physical measurement; coordinates that system with measurement systems of other nations; and furnishes essential services leading to accurate and uniform physical measurements throughout the Nation's scientific community, industry, and commerce. The Institute consists of a Center for Radia-tion Research, an Office of Measurement Services and the following divisions:

Applied Mathematics-Electricity-Heat-Mechanics-Optical Physics-Linac Radiation ${ }^{2}$ - Nuclear Radiation ${ }^{2}$ - Applied Radiation ${ }^{2}$ - Quantum Electronics ${ }^{3}$ Electromagnetics ${ }^{3}$ - Time and Frequency ${ }^{3}$ - Laboratory Astrophysics ${ }^{3}$ - Cryogenics ${ }^{3}$.

THE INSTITUTE FOR MATERIALS RESEARCH conducts materials research leading to improved methods of measurement, standards, and data on the properties of well-characterized materials needed by industry, commerce, educational institutions, and Government; provides advisory and research services to other Government agencies; and develops, produces, and distributes standard reference materials. The Institute consists of the Office of Standard Reference Materials and the following divisions:

Analytical Chemistry-Polymers-Metallurgy-Inorganic Materials-Reactor Radiation-Physical Chemistry.

THE INSTITUTE FOR APPLIED TECHNOLOGY provides technical services to promote the use of available technology and to facilitate technological innovation in industry and Government; cooperates with public and private organizations leading to the development of technological standards (including mandatory safety standards), codes and methods of test; and provides technical advice and services to Government agencies upon request. The Institute also monitors NBS engineering standards activities and provides liaison between NBS and national and international engineering standards bodies. The Institute consists of the following divisions and offices:

Engineering Standards Services-Weights and Measures-Invention and Innovation-Product Evaluation Technology-Building Research-Electronic Technology-Technical Analysis-Measurement Engineering-Office of Fire Programs.

THE CENTER FOR COMPUTER SCIENCES AND TECHNOLOGY conducts research and provides technical services designed to aid Government agencies in improving cost effectiveness in the conduct of their programs through the selection, acquisition, and effective utilization of automatic data processing equipment; and serves as the principal focus within the executive branch for the development of Federal standards for automatic data processing equipment, techniques, and computer languages. The Center consists of the following offices and divisions:

Information Processing Standards-Computer Information-Computer Services - Systems Development-Information Processing Technology.

THE OFFICE FOR INFORMATION PROGRAMS promotes optimum dissemination and accessibility of scientific information generated within NBS and other agencies of the Federal Government; promotes the development of the National Standard Reference Data System and a system of information analysis centers dealing with the broader aspects of the National Measurement System; provides appropriate services to ensure that the NBS staff has optimum accessibility to the scientific information of the world, and directs the public information activities of the Bureau. The Office consists of the following organizational units:

Office of Standard Reference Data-Office of Technical Information and Publications-Library-Office of International Relations.

\footnotetext{
1 Headquarters and Laboratories at Gaithersburg, Maryland, unless otherwise noted; mailing address Washing- 


\section{Calibration of Secondary \\ 731 Standard Magnetic Tape Cassettes (Computer Amplitude Reference) Phase I}

Sidney B. Geller and Paul A. Mantek

Information Processing Technology Division Center for Computer Sciences and Technology

U.S. National Bureau of Standards

Washington, D.C. 20234

\section{t. Technical note no 731}

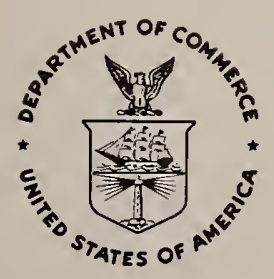

U.S. DEPARTMENT OF COMMERCE, Peter G. Peterson, Secrełary NATIONAL BUREAU OF STANDARDS, Lawrence M. Kushner, Acting Director. Issued July 1972 
National Bureau of Standards Technical Note 731

Nat. Bur. Stand. (U.S.), Tech. Note 731, 60 pages (Jul y 1972) CODEN: NBTNAE

For sale by the Superintendent of Documents, U.S. Government Printing Office, Washington, D.C. 20402 (Order by SD Catalog No. C13.46:731). Price 60 cents. 
1. INTRODUCTION. . . . . . . . . . . . . . . . . I

2. DIGITAL MAGNETIC TAPE CASSETTES . . . . . . . . 4 2.I Digital Cassette Applications. . . . . . . 4

2.2 Digital Cassette Construction. . . . . . . 5

2.3 Digital Cassette Transports. . . . . . 8

3. EXPERIMENTAL DESIGN FACTORS IN THE REFERENCE

CASSETTE PROGRAM. . . . . . . . . . . . . . . . 9

3.1 Development of Cassette Groups . . . . . . 9

3.2 Statistical Considerations . . . . . . . . 9

3.3 Development of Transducer Groups . . . . . 10

3.4 Summary............... 13

4. THEORY OF OPERATION OF THE NBS CASSETTE SIGNAL

AMPLITUDE MEASUREMENT SYSTEM. . . . . . . . . 14

4.1 System Components. . . . . . . . . . . 14

4.2 Description of the System Operation. . . . 17

4.3 Description of the OA-4 Circuit. . . . . . 24

5. EXPERIMENTAL RESULTS. . . . . . . . . . . . 26

5.1 Case Histories of Submitted Cassette

5.2 Cassette Transports Used for Measurements. . 26

5.3 Experimental Measurement Data... . . . 30

6. COMPONENT LIST. . . . . . . . . . . . . 52

7. APPENDIX. . . . . . . . . . . . . 53

7.1 Digital Cassette Standardization Progress. . 53

7.2 Tape and Leader Dimensions . . . . . . 53

8. REFERENCES. . . . . . . . . . . . 55

LIST OF FIGURES

Figure

Number

1 Physical details of a digital magnetic tape cassette............... . 7

2 Block diagram of the interim NBS signal amplitude measurement system. . . . . . 15 
3 Block diagram of the interim NBS read channel measurement system. . . . . . . 18

4 Read system input circuits. (LD-IC, $\mathrm{AT}-\mathrm{IC})$. . . . . . . . . . . . . . 19

5 Read system preamplifier $(W P R-1)$. . . . . 20

6 Read system peak detect-sample-and-hold system $(\mathrm{PD}-\mathrm{SH}-1, \mathrm{OA}-2, \mathrm{OA}-3)$. . . . . . 21

7 Read system output circuits (OA-4, OA-9, $\mathrm{OA}-10$. . . . . . . . . . . . 22

8 Cassette transport speed measurement curves. . . . . . . . . . . . . 38

9 Cassette transport speed measurement curves. . . . . . . . . . . . . 39

10 Tape tension test curves......... . 40

11 Tape tension test curves. . . . . . . . 4 I

12 Cassette torque test curves . . . . . . 43

13 Signal amplitude histogram for runs 1 to 15 . 44

14 Signal amplitude histogram for runs 1 to 6. . 45

15 Signal amplitude histogram for runs 7 to 12 . 46

16 Signal amplitude histogram for runs 13 to 15.47

17 Six track chart recorder output curves. . . . 49

18 Six track chart recorder output curves. . . 50

$19 \phi-\mathrm{H}$ loops for four cassettes. . . . . . 51 
CALIBRATION OF SECONDARY STANDARD MAGNETIC TAPE CASSETTES (COMPUTER AMPLITUDE REFERENCE) PHASE I.

Sidney B. Geller and Paul A. Mantek

This Technical Note discusses a method for developing and majntaining a reference system which will produce NBS Secondary Standard Magnetic Tape Cassettes (Computer Amplitude Reference). It describes both centerline tape search procedures and an interim signal amplitude measurement system for the reference magnetic tape cassette candidates. The results of the initial experiments with cassette tapes and transports are given.

Key words: Cassette tapes; cassette transport; computer amplitude reference; magnetic tape cassette; secondary standard; standard reference material; unrecorded references.

\section{INTRODUCTION}

At the request of industrial users of computer cassette tapes, Government procurement agencies, producers of magnetic computer tapes, and producers of cassette tape handling equipment, the National Bureau of Standards is developing a signal amplitude measurement system and will eventually supply unrecorded Secondary Standard Magnetic Tape Cassettes (Computer Amplitude Reference) through the NBS Office of Standard Reference Materials.

This Technical Note describes the activities in the signal amplitude reference magnetic tape cassette program which is being performed in the NBS Center for Computer sciences and Technology. The methods that were used for developing the continuing NBS signal amplitude computer reference tape (reel-to-reel) program are briefly described and are being used as a guide for the cassette program.

An actual reel of magnetic tape or a magnetic tape cassette is the only practical tool that is presently available for adjusting and calibrating the signal amplitude response of a magnetic tape or cassette recording system. The performance of one of these particular reels or cassettes must typify the performance of the tapes in its own category in order that maximum interchangeability of such storage media can be achieved.

Once a system has been calibrated with a reference cassette then: 
(1) The manufacturer of cassettes can maintain production controls by comparing the output signal level from his newly made tape cassettes to the pre-set referenc'e signal level as they are run and measured on a system which has been calibrated with the reference cassette. For example, a manufacturer can adjust his fabrication processes to produce tapes with a signal level variation of at most $+10 \%$ from the reference signal level that he has pre-set with his reference tape.

(2) The manufacturer of tape handling equipment can design his transducers, guidance systems and electronics to perform in an optimum fashion with the reference signal levels.

(3) The tape user can assume with some confidence that most tapes in the same category as the reference tape will operate within given margins in his calibrated tape system, i.e., good tape interchangeability can be achieved. This would be especially valid if all of the industry reference tapes were originally calibrated with respect to the same primary reference tape group.

NBS is presently calibrating and issuing the unrecorded signal amplitude reference tape reels which are officially described as "NBS Secondary Standard Magnetic Tape - (Computer Amplitude Reference) SRM-3200. In order to qualify in this category, each tape reel undergoes a screening process to determine its signal amplitude uniformity at all recording densities as well as its signal output level relative to that obtained from a particular tape described as the "NBS Master Standard Magnetic Tape - (Computer Amplitude Reference).

The NBS computer reference magnetic tape program has been accomplished in the following four major phases which will be duplicated in the reference cassette program:

Phase 1: The development of a signal amplitude measurement system for reference tapes $[1]^{1}[2]$.

Phase 2(a) The determination of the unrecorded NBS Primary Master Standard Magnetic Tape - (Computer Amplitude Reference) group and its utilization and maintenance in repository,

${ }^{1}$ Figures in brackets indicate the literature references on page 56. 
Phase 2(b) The determination of the unrecorded NBS Secondary Standard Magnetic Tapes - (Computer Amplitude Reference) group and its utilization and maintenance in repository. These secondary group tapes are not the SRM 3200's.

Phase 2(c) The determination and production on a continuing basis of "Working" signal amplitude reference tapes to be used during the SRM 3200 calibration runs.

Phase 2(d) The determination of both a reference read/ write transducer group to remain in repository and a "Working" read/write transducer group for use in performing calibration runs. The "Working" transducers are sought on a continuing basis.

Phase 3: The industry and government evaluation and acceptance of the NBS results of the two preceding phases.

Phase 4: Calibration and issuance of the SRM-3200 unrecorded signal amplitude reference tapes. This includes all associated information such as a certificate, measurement charts and descriptive literature such as the NBS Special Publication 260-29 [2].

The application of the same program phases to the cassette program will now be discussed:

Phase 1: This has been partially fulfilled through the design of some new circuits which operate in conjunction with modified sections of the reference tape signal amplitude measurement system described in [2]. This is described in section 4. Initial measurement results are described in section 5 .

Phase 2: There are critical differences in the cassette program options for accomplishing Phase $2(\mathrm{a})$. This will be the area of greatest difficulty because, while the SRM-3200 program was based upon existent de facto industry standard reference tapes, none exist in the tape cassette field. Possible approaches to the problem in the absence of similar de facto standard cassettes are outlined in section 3 . The completion of Phase 2 (a) in conjunction with Phase 2(d) should lead to the certain completion of Phases $2(b)$ and $2(c)$.

Phase 3: This phase will probably take the form of a round-robin test procedure similar to that performed with the reel tape. These SRM-3200 tests and their results were as follows: 
After the NBS tape laboratory obtained the NBS primary Standard Magnetic Tape - (Computer Amplitude Reference) Group a number of candidate reels of tapes were calibrated with respect to it on the amplitude measurement system. Those tapes that fell within the certified signal uniformity and level specifications were designated as NBS Secondary Standard Magnetic Tapes - (Computer Amplitude Reference). Eighteen of these tapes were submitted for evaluation to industrial organizations including of both tape producers and tape equipment manufacturers who used them to calibrate their tape handling systems. These calibrated systems were then used to compare the signal amplitude from the NBS tapes relative to their "own" in-house reference and control tapes. The results of the survey were gratifying in as much as the NBS reference signal levels were well situated in a scatter plot that showed the relationship of the industry reference levels to the NBS level. However, some of the tape manufacturers felt that the deviation in their reference levels from the NBS level was due mainly to the variations in the different read/write head signal amplitude responses. This difference commonly occurs even among heads of the same type produced in the same plant. It is felt by both industry and the NBS laboratory that it is very important to investigate both head-to-tape interaction effects and the problems and causes of the variation in response from head-to-head. This concern also exists for cassette transducers and it is felt that solutions for the overall magnetic transducer problem should be given high priority. This would be an important step towards the design of a "standard" head. It is also felt that the head problems will be compounded by the various types of pressure pads in the cassettes that do not exist in the reel-to-reel tapes.

Phase 4: This phase is dependent upon industry negotiated requirements that will eventually be specified on the certificate which accompanies each reference cassette tape. For example, the SRM-3200 is calibrated at the bit densities of 3200 , 1600,800 and 200 frpi. The present cassette specifications call for testing at 1600 frpi - saturated recording.

\section{DIGITAL MAGNETIC TAPE CASSETTES}

\subsection{Digital Cassette Applications}

There are three principal applications for digital cassettes: ( 1 ) data terminals, (2) data acquisition systems, and (3) minicomputers. In data terminals the digital cassette performs the task of data loading and storage; in many cases this is done at remote terminals. The cassette is also used to receive and transmit data over telephone lines. Data acquisition systems usually involve keyboard 
entry of information on an incremental basis into a lowcost cassette system. These applications include the use of such instruments as typewriters, cash registers, or accounting machines. In minicomputers the cassette is used for input, output, and auxiliary storage in the same way that magnetic tape is used in large scale computer tape transports. Cassettes are also replacing punched paper tape and punched cards in industrial processing systems and numerically controlled machines.

\subsection{Digital Cassette Construction}

(Philips Type)

The Philip's type of audio cassette which is referred to as the "compact cassette" was developed by Philips Electrologica of Eindhoven, Holland. This is the most prevalent type of cassette that is used for digital applications and is produced under a cost-free license by a large number of companies. follows:

Physical details of the Philip's type cassette are as

In most cases, the outside shell of the cassette is made of a noninflammable, high impact polystyrene plastic. One model is available with a metal shell. The shell consists of two pieces which are joined together either with screws near the four corners or by ultrasonic welding. The welded cassette cannot be opened without destroying the shell.

The front edge of the cassette shown in Figure la has 5 holes which serve the following functions: holes $A$ and E are for pinch rollers (usually solenoid activated) which enter the cassette and engage capstans which are directed into holes $A^{\prime}$ and $E^{\prime}$ ( $f$ igure $l b$ ). when the cassette is inserted into the transport; holes $B$ and/or D are used for BOT/EOT optical sensing and hole $B$ for an erase head when one is used; hole $C$ is used for the record and/or read head. The side view (figure lb) shows the location of the pressure pad $F$. There is no general agreement about the need for a pressure pad; some transports require a pad, while others are unable to use a cassette with a pad.

The back edge of the cassette (figure lc) has two Ushaped cuts in the shell which enclose areas that can be punched out to allow read only operation. A write enable plug can be inserted into these areas when a write operation is desired. The use of this write enable plug has not been entirely satisfactory because it is small in size and is easily lost. One cassette manufacturer covers the hole with 
a metal plate inside of the cassette so that it can be "read-only" or "write enabled" by rotating a small disc that is built into the side of the cassette. This controls the opening or closing of the hole when the write enable sensing pin in the transport engages the metal plate. The dotted square to the left of center (figure lc) is a hole which is specified in the ECMA standard and is used to identify the $A$ and $B$ sides of the cassette. At the present time, the American manufacturers are avoiding this means of identification and instead prefer to label the A side of the cassette in the area reserved for labels. Area $\mathrm{H}$ (figure lb) contains a transparent window on both sides of the cassette to enable the user to view the tape on both hubs.

The tape is wound on 2 flangeless hubs within the cassette. These hubs are loosely fit in order to allow for the easy engagement of the tape supply and take-up drive shafts. One manufacturer has used precision mounted ball bearing tape hubs in the cassette shell. A hub usually has provisions for fastening the tape leader to its outer surface. Rollers are provided at position J (figure lb) for tape guidance. There are several configurations for these rollers. In one model they are spring loaded in order to fix their position in the cassette and the tape contacting surface is convex shaped to keep the tape centered on this roller surface. In another case, the rollers are free to move between the cassette shells and the important tape guidance is performed closer to the head.

The inside surfaces of the large sides of the cassette shell contain a liner which is called a "slip sheet". These are usually made of a plastic material which provides a low friction surface for the tape pack to slide and rotate against. One model has convex ribs onto the slip sheet which causes the tape to be forced gently into a uniform pack on the hub. It is also claimed that this design will reduce dynamic skew. This is accomplished with an increase in friction which must be overcome by the driving source.

Since cassette tape is not held taut between the hubs when a cassette is removed from the transport, the outer tape layers tend to loosen from the pack due to handling. Therefore, there is an abnormal space between the hub and slip sheet, the outer layer may slide into this space and cause a tape jam-up. Provisions are usually made in digital cassette containers to prevent the loosening of the tape pack during storage. This is accomplished with 2 fixed posts in the container which engages the hub centers. 


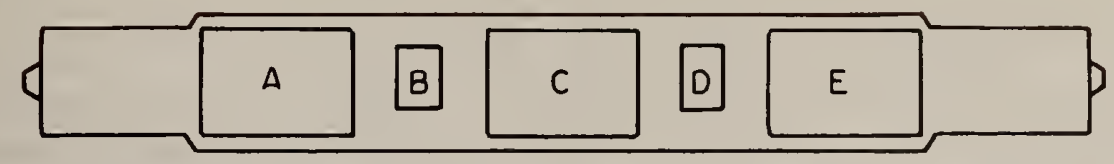

a. Front Edge

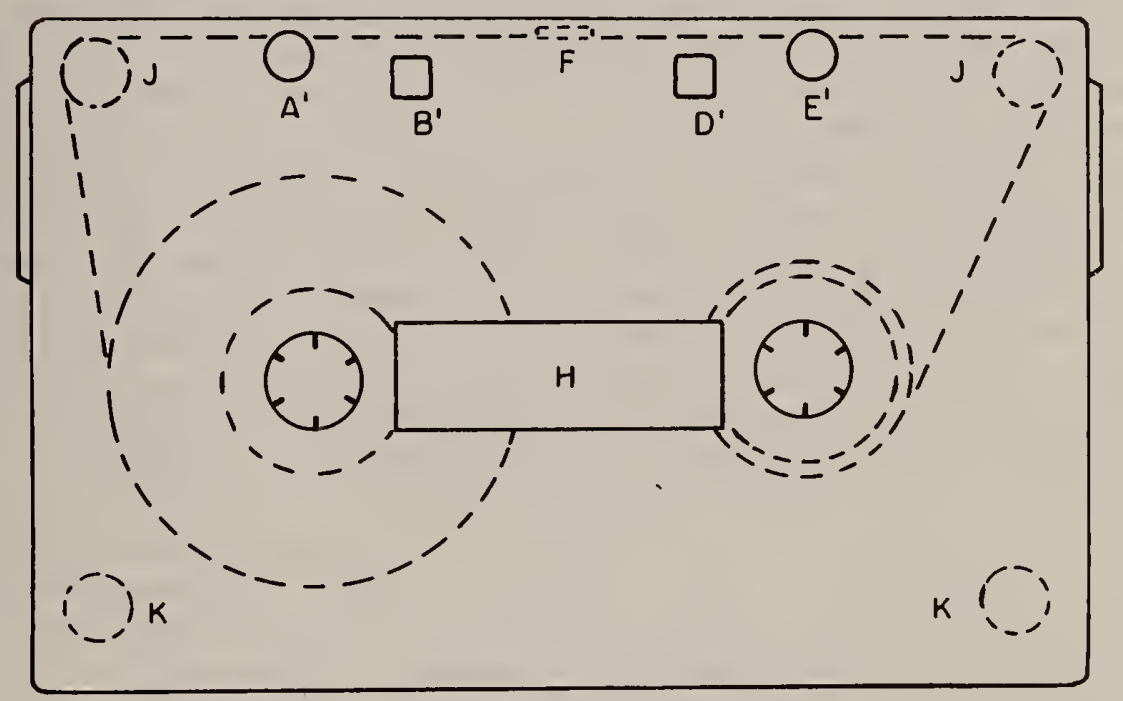

b. Side view

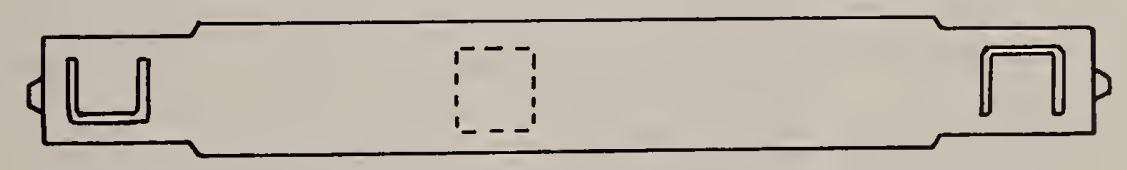

c. Back View

Figure 1. Physical details of a digital magnetic tape cassette 
There is considerable activity in the area of compact cassette digital transport development and manufacture. Most of the companies either did not exist until recently or are new to the digital transport field. It is also interesting to note that to date no major digital computer manufacturer has produced a compact cassette transport for the commercial market, although some have submitted proposals for a cassette with a wider and thicker tape.

The lack of digital cassette standards has allowed transport manufacturers to proceed into different directions with their designs. Some of the transports were designed and built to operate with a specific system while many from both this group and othershave been made available to the OEM market with a large number of options. In many cases the mechanical transport unit is available with a head, read and/or write electronics, servo speed control, choice of speed, incremental and/or continuous operation and other options. Transports with heads and electronics are available for the following operations: (1) read only, (2) write only, (3) write pass then read pass, and (4) read-whilewrite pass. Many of the heads that are now in use were originally designed for audio operation, but some are now available that were designed specifically for digital use.

There is a variety of available operating characteristics in digital transports. For example: Tape "slow-forward" speed can be obtained from $1-7 / 8$ to 15 inches per second with 5 to 6 inches per second being typical. Some units have the same "slow-forward" and "reverse" speed, others have only a "high speed reverse" and still others also have a "high speed forward". Tape movement in the "slow-forward" and "reverse" speeds is usually performed with 2 pinch rollers and capstans; in some transports this is done with one capstan and one pinch roller in which the capstan rotation is reversed. In at least one unit both pinch rollers are activated to move the tape while in another unit the capstans have been eliminated and tape motion is controlled entirely by the reel motors. Incrementally operated transports are also available and in some cases the transport is able to operate in either the continuous or the incremental mode.

Section 5 discusses the specific digital cassette transports that were used in the signal amplitude experiments in this first program phase. 
3. EXPERIMENTAL DESIGN FACTORS IN THE REFERENCE CASSETTE PROGRAM

\subsection{Development of Cassette Groups}

The reference digital cassette program is proceeding along lines which are similar to those of the SRM-3200 program as outlined in the introduction. The major activity will consist of the development of the primary and secondary reference cassette groups by conducting a statistical search for industry "centerline" signal level. The statistical search is required because there is no de facto reference cassette. The physical embodiment of the "centerline" signal level will eventually be in the primary reference cassette group. One tape in this group will be designated as the NBS Master Standard Cassette (Computer Amplitude Reference) on the basis of factors such as its position in the primary group signal level distribution, and its signal amplitude stability and uniformity characteristics. Once the NBS Primary Standard Cassette (Computer Amplitude Reference) Group has been developed it will be used to calibrate the NBS measurement system in order to develop the secondary and "working" reference cassette groups. Classically, a secondary reference group is used as a comparison medium for monitoring the stability of the primary group in repository and is usually constructed from different materials. The "working" groups are used for the day-to-day system calibration procedures.

\subsection{Statistical Considerations}

In order to develop a properly randomized sample of digital cassettes, it is necessary to consider questions such as the following:

The size of the required sample is a function of the signal level variability of the individual cassette tapes. What is this variability and can it be determined other than by extensive measurements and experimentation? In order to have a valid statistical experiment with properly randomized data, we must know a number of things about every tape cassette under investigation. For example, who manufactured it? Are the lot numbers different for cassettes purchased from a particular manufacturer? Has the tape been manufactured by still current techniques or is it obsolete? Is it possible that some cassettes are the result of a momentary loss of quality control? Is it a special reel or an off-the-shelf item? How much does the tape vary in output along its length and across its width? Since the same output is not obtained from the tape after each pass, what is the pass criterion? Should 
the data be weighted according to company sales volume? If so, what is that volume? Does this tape come from the primary source or has it been channeled through a secondary source which has altered it in some way?

The following are three possible approaches for obtaining the sample cassettes from which the statistical signal level data can be measured:

(1) Purchase through various external sources possibly located in different geographical areas) groups of say, 20 each of every magnetic tape cassette which is commercially marketed in a particular category from every manufacturer of that particular category. If possible, each cassette should be derived from a different production run (note the lot numbers). Also the history of each cassette should be known including the production date, the plant location and if the tape has been subjected to any unusual secondary postprocessing.

(2) Or, directly contact all cassette manufacturers in the category of interest and see if they will submit samples to NBS of groups of tapes which represent the average and upper and lower limits in each cassette category.

(3) Or, purchase groups of all the available company reference tapes in each category of interest. This option may be a very effective approach particularly if the reference tapes do in fact represent production average tapes. Probably a combination of $A$ and $C$ or $A$ and $B$ would be most efficient. For example, in making measurements in each tape category it is possible to use the corresponding reference tape to calibrate the electronics and transport before measuring each of the associated cassettes.

\subsection{Development of Transducer Groups}

The "centerline" search cannot proceed without a simultaneous search for the reference transucers, i.e. the read/write heads. The head-to-tape interaction effects do not permit either the tape or the head to be characterized or completely analyzed independently of the other. That is, the relative signal amplitudes that are read from a group of recorded tapes can vary significantly from head to head. The state-of-the-art of magnetic tape transducer design has not yet produced an acceptable "standard" read/ write head. That is, the tape head industry is not able to construct a head that is reproducible, stable, compatible with existent commercial equipment and understood analytically. For this reason, it is likely that the interim reference 
cassette transducer groups will consist of commercially available read/write heads. The first series of tests that are reported in section 5 were made with such commercially available heads. The introduction of a head-to-tape pressure pad into the digital cassette adds another complicating factor. It has been found that both the absolute pad pressure and the pad material will affect the signal response of the cassettes.

The following are the type of criteria that must be applied in order to develop the commercialy available transducer group:

(1) Locate the individual head type (or types) which tend to show maximum signal amplitude reproducibility among the same cassettes. That is, there should be a reasonable probability that heads with similar characteristics are available in the market place and are not one-of-a-kind items. This can only be ascertained by random sampling and measurement.

(2) The break-in time criteria must be investigated; i.e., the length of time that is required for the head response to stabilize. For example, in the SRM-3200 program the average heads were run in for approximately 15 to 25 hours before being used for calibration purposes.

(3) The end-of-life criteria must be developed; that is the point at which the usefulness of a head as a calibrating device must be known. This depends upon factors such as:

(a) The changes in the original relative signal level response of the head which becomes apparent when the measurements performed on a group of test cassettes become different as the head wears. In order to check the stability of the test cassettes themselves, it is necessary to maintain a test head that is seldom used. In this way any changes in the response of the test cassettes can be detected by re-measuring them with this test head periodically.

(b) Changes in the reproduced signal smoothness: for example, this is manifested by a "hashy" appearance in the signal peak trace as shown in Figure 18.

(c) Unusual increase in absolute output signal amplitude: This may indicate that the depth of the head at the gap has narrowed significantly.

After the digital cassette samples and interim transducers have been obtained, the following experimental decisions must be made: 
(1) The form of the information which is written onto these cassette tapes: For example, mode: NRZI or phase encoding; bit density; write current level; write current shape; continuous pulse train or information blocks, ac, dc or bulk erase prior to recording,

(2) The method of extracting the recording information and its form: For example, peak or average peak value; peak-to-peak or average peak-to-peak value; read-while-write; read-after-write (which pass?),

(3) There is a wide range of available cassette transport speeds, therefore, the same bit density can result in a number of different output signal frequencies. This affects the transducer and electronics design factors. The decisions for the first experimental program phase were as follows:

(a) The writing density and mode: 1600 frpi (NRZI).

(b) The write current levels were the fixed design values determined by the cassette transport that was used.

(c) The write currents were square wave driven without an initial step current.

(d) Continuous pulse train recording (All "I's").

(e) The cassette tapes are ac bulk erased before recording.

(f) The peak and average peak; the peak-to-peak and average peak-to-peak information are all measured simultaneously and recorded on a 6 track chart recorder. are measured.

(g) The fourth or greater read-after-write passes

(h) Six cassette transports were used with speeds ranging from 4 to 12 inches per second. This results in operating frequencies from $3.2 \mathrm{kHz}$ to $9.6 \mathrm{kHz}$.

The background for these initial decisions is based upon the experience gained in the SRM-3200 program and upon existing digital cassette specifications and industry trends. It is possible, however, that some of these conditions will be changed as more experimental data are accumulated. 


\section{4 Summary}

(1) Establish a reservoir of digital cassette tapes that can be used as a random sample source.

(2) Obtain a number of available digital cassette transports - at least 10 if possible.

(3) In addition to the read/write heads that normally accompany each cassette transport, obtain additional replacement heads for each model.

(4) Develop a signal amplitude measurement system whose gain-frequency characteristics are compatible with the above digital cassettes and cassette transports.

(5) Now apply the operating conditions described in the previous paragraph to measure the signal amplitude response of the cassette samples.

(6) Calibrate the measurement system so that the range and the relative signal amplitude of the cassettes can be conveniently charted. The charts information can then be organized into statistical form.

(7) From the statistical data locate a group of cassettes that is central to the distribution from a modal. and median point of view.

(8) Reorganize the descriptive statistical data into a form which displays the centrally located signal amplitude as the $100 \%$ reference level and all others levels dispersed about it in their relative positions on a percentage basis.

(9) Repeat steps 5 through 8 with each transport and replacement heads. Set aside those units that show similar, reproducible and uniform results for use as possible interim references.

(10) Study the measurement data that are derived from all the preceding runs and determine that group of 5 digital cassettes which appears most often in the center of a signal amplitude distribution. Place this group into repository as the interim primary cassette group. This group now sets the $100 \%$ signal level for its entire category. 
4. THEORY OF OPERATION OF THE NBS CASSETTE SIGNAL AMPLITUDE MEASUREMENT SYSTEM

The system which is used for making the cassette signal amplitude measurements consists of both circuit modifications and newly designed additions to the NBS reference tape signal amplitude measuring system [2]. This new configuration measures and simultaneously charts the following output signal amplitude data on a 6 track chart recorder: [See figures 17 and 18$]$.

(1) Negative peak amplitude (Track l).

(2) Average negative peak amplitude (Track 2).

(3) Positive peak amplitude (Track 3).

(4) Average positive peak amplitude (Track 4).

(5) Peak-to-peak signal amplitude (Track 5).

(6) Average peak-to-peak signal amplitude (Track 6).

This variety of output data will be useful for making experimental decisions. Eventually, one data format will prevail as the industry standard. The present trend appears to favor the peak-to-peak measurements because they reduce the effects of asymmetry in the writing process. That is, the method of erasure and the write head current balance causes less reproduce error in a peak-to-peak than in a zero-to-peak measurement. Peak-to-peak measurements also tend to reduce the effects of loose experimental control, particularly in recorded tape tests.

\subsection{System Components}

Figure 2 shows the organization of the initial system that will be used for measuring and calibrating the unrecorded NBS Secondary Standard Magnetic Cassette Tapes (Computer Amplitude Reference). The system consists of a signal amplitude read channel, a supply voltage section which includes a precision voltage dividing network and a switching system for use in both the operation and the calibration of the system. Various readout instruments are also included in the system.

This first phase report does not include a write circuit because one cannot be designed until an interim reference head or group of heads has been chosen. At that time, it will be designed as a continuous write current controlled system which is capable of producing sets of saturation 


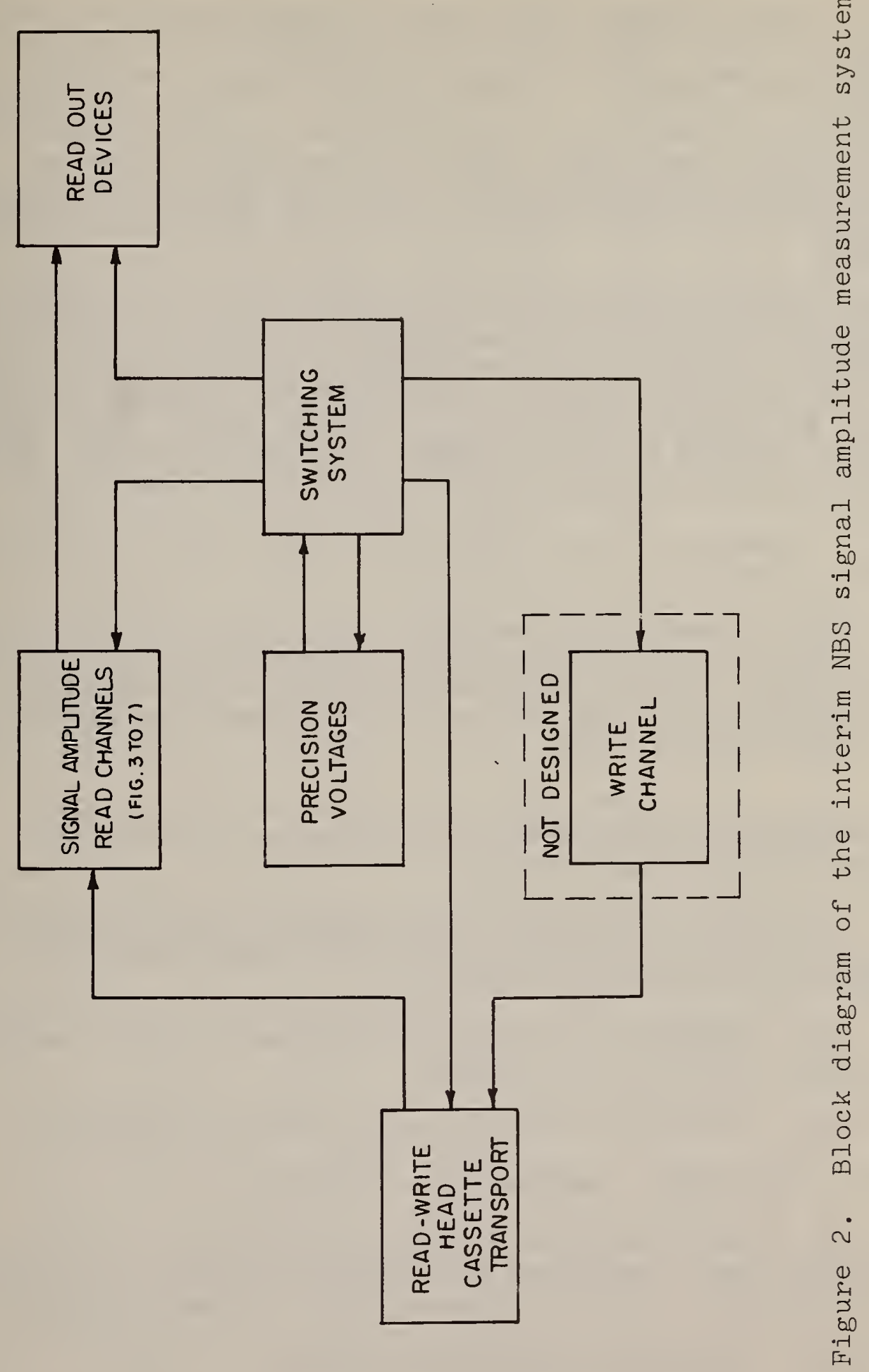


curves. These curves relate the read head output voltage versus the write head current as described in reference [2]. The write current circuits will eventually be automated and externally controlled. In the absence of these circuits the series of tests that are described in section 5 were accomplished by recording the cassettes with the write current levels already found in the test cassette transports. These are fixed current values that were set by the manufacturers.

The following descriptive material lists the components that appear in each of the sections or channels. One of the figures contains the block diagram of the channel functions and the other figures consist of the circuit realizations of the block functions. Note that within most of the individual blocks a figure number is inscribed which identifies the circuit diagram that corresponds to that block.

(1) Cassette Signal Amplitude Read Channel Components (figures 3 to 7 ).

(a) A read/write head and associated cassette transport, a line driver LD-1C, a termination network TE-IC, and attenuator circuit AT-IC and a wideband preamplifier WPR-l with internal and external gain potentiometers $R_{3}$ and $R_{4}$ and amplifier $\mathrm{OA}-1$.

(b) Peak detect-sample-and-hold circuit PD-SH-I that contains comparator IC-1, transistors $\mathrm{T}_{6}$ through $\mathrm{T}_{14}$, and diodes $\mathrm{D}_{1}$ through $\mathrm{D}_{4}$.

(c) Level shifting, inverting range setting and summing circuits containing operational amplifiers OA-2 through $\mathrm{OA}-5, \mathrm{OA}-8$ through $\mathrm{OA}-10$.

(d) External 10-turn potentiometers $\mathrm{R}_{5}$ for setting the "MASTER GAIN" of the system.

(e) Passive R-C signal peak averaging circuits.

\section{(2) Auxiliary Components and Systems}

(a) Four precision voltage sources $(+6.0, \pm 14.0$, +30.0 volts) and a dividing network for providing $\overline{d c}$ calibration voltages. One precision digital voltage source.

(b) A function switching system.

(c) Read-out devices: a 6-track chart recorder, a digital panel meter DPM-l and a digital voltmeter DVM-l. An $X-Y$ recorder will be added when the write circuits are designed. 
(1) Cassette Signal Amplitude Read Channel Operation (figures 3 to 7 ).

(a) The signal which has been reproduced during a read-after-write operation from a test cassette is passed through the unity gain, line driving amplifier LD-lC which is physically located at the read head. The line is terminated by TE-IC and network AT-IC. AT-IC attentuates the incoming signals so that the input to the WPR-l preamplifier will fall within a reduced range of amplitudes for the different recording densities. AT-IC is adjusted with $R_{l}$ and $R_{2}$. Thus far, typical values of output signal from LD-lC have been found to lie in the range of $6.0-12.5 \mathrm{mV} p / \mathrm{p}$ at 1600 frpi. This variation in head output voltage is caused by both the differences in read head design and the greater than 2:1 variation in transport speeds.

The preamplifier was adjusted with $R_{3}$ so as to produce an average output voltage of approximately 6.0 volts $\mathrm{p} / \mathrm{p}$ when the input was read from the interim "master" cassette. This is a convenient starting value which produces good linear response from the system. The principal deviation from the operating philosophy of the computer tape signal amplitude measuring system is as follows: (See figures 3 and 5 ).

In the original system 3 WPR-I wide-band preamplifier stages were used to amplify the output signals from three read head tracks while in the cassette system only one WPR-1 is required. In the original system each of the WPR-l's drove a separate sample-and-hold circuit which in turn fed its respective signal into individual level shifting amplifier $\mathrm{OA}-2$ and summing amplifier $\mathrm{OA}-4$. The adaptations for the cassette signal amplitude measurement system are as follows: The signal from the WPR-l is fed simultaneously into the sample-and-hold circuit PD-SH-lA and into the unity gain inverter OA-8 whose output is then fed into PD-SH-1B. In this way both the positive and negative signal peaks are each passed through their own channels. PD-SH-lB processes the positive peaks and the PD-SH-lA processes the negative peaks. The two peak-detect sample-and-hold circuits convert their ac input signals into dc levels that are equal to their peak values. 3.000 volts de represents the $100 \%$ level for the measuring system and all output levels are described in terms of their value as a percentage of 3.000 volts.

The peak detect-sample-and-hold circuits PD-SH-l in figure 6 operates as follows: 


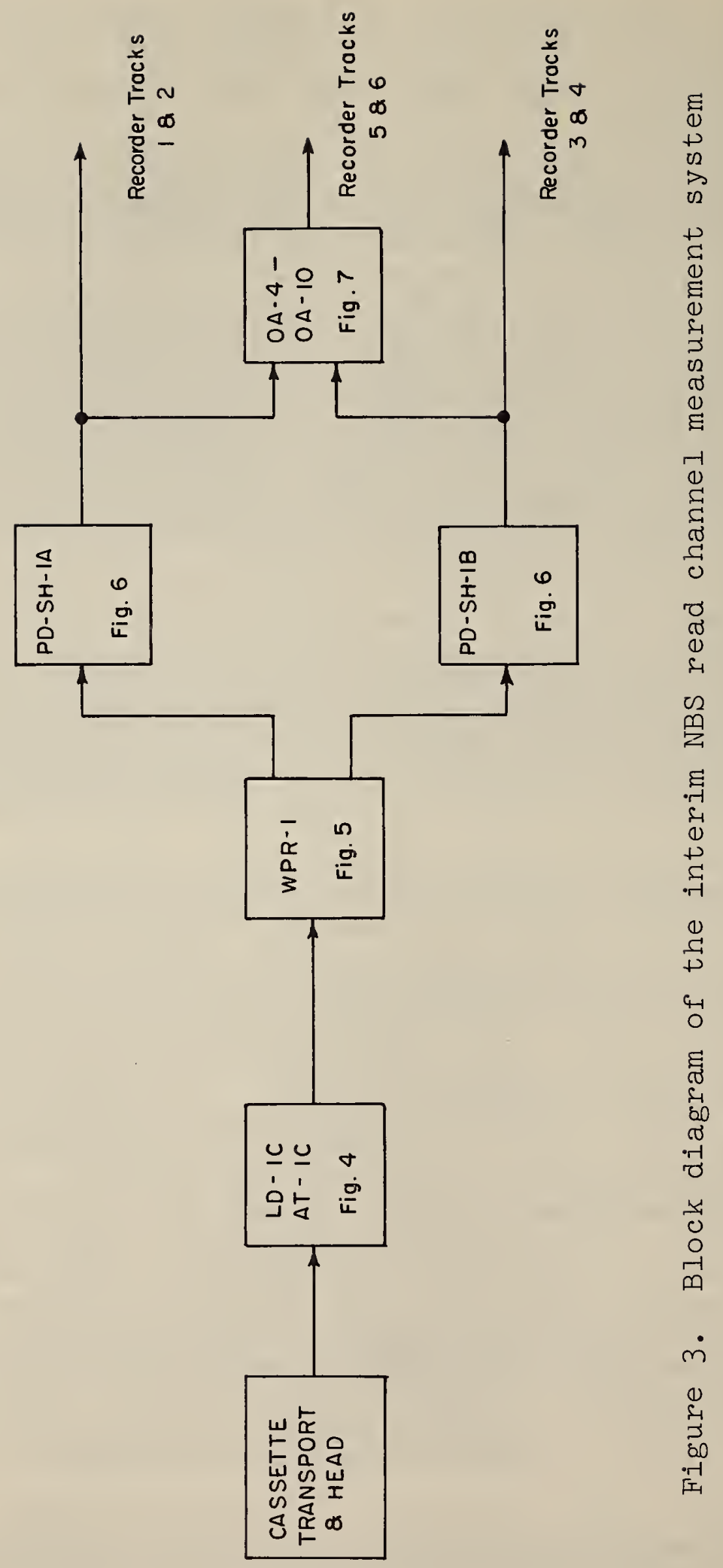




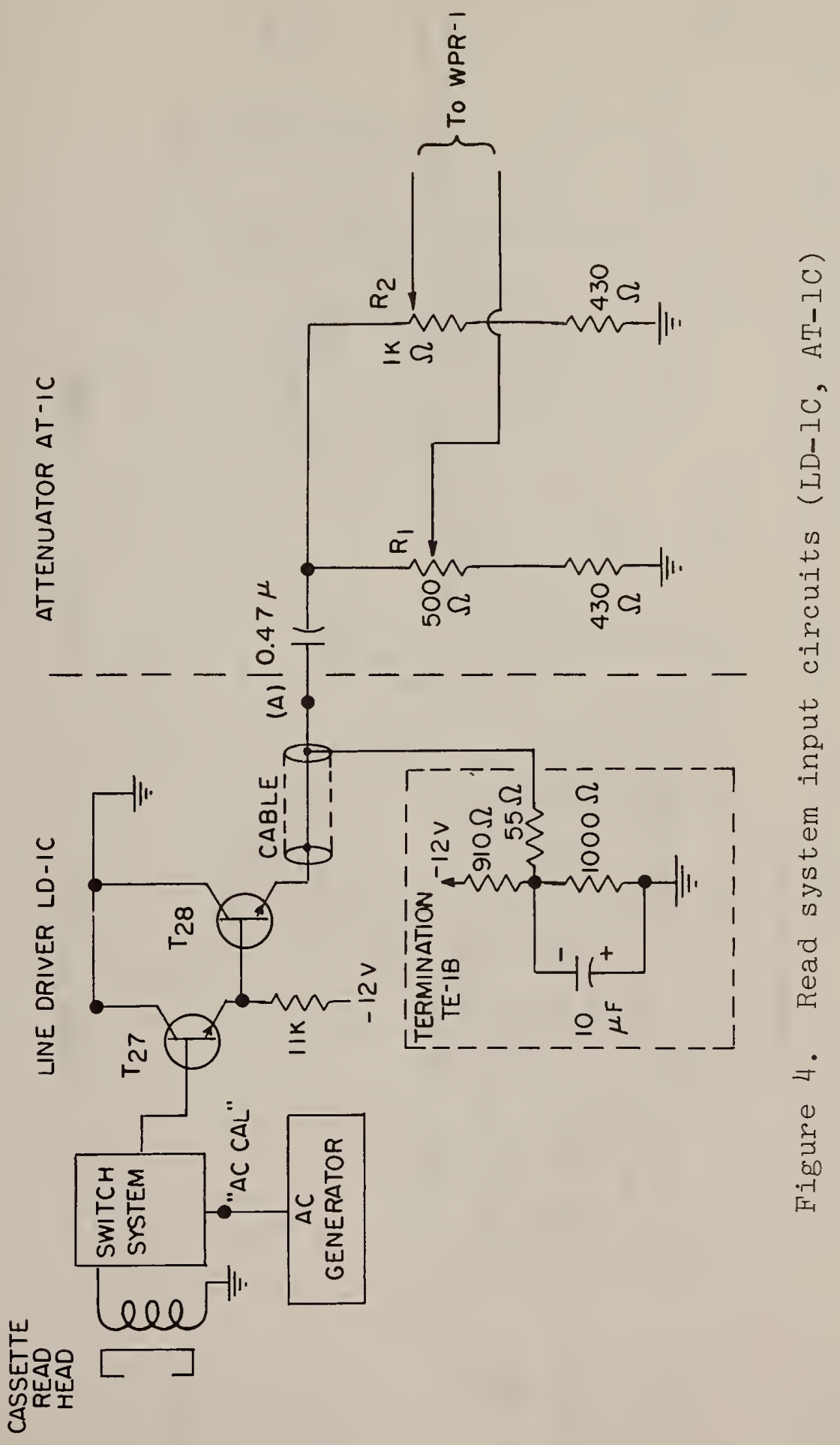




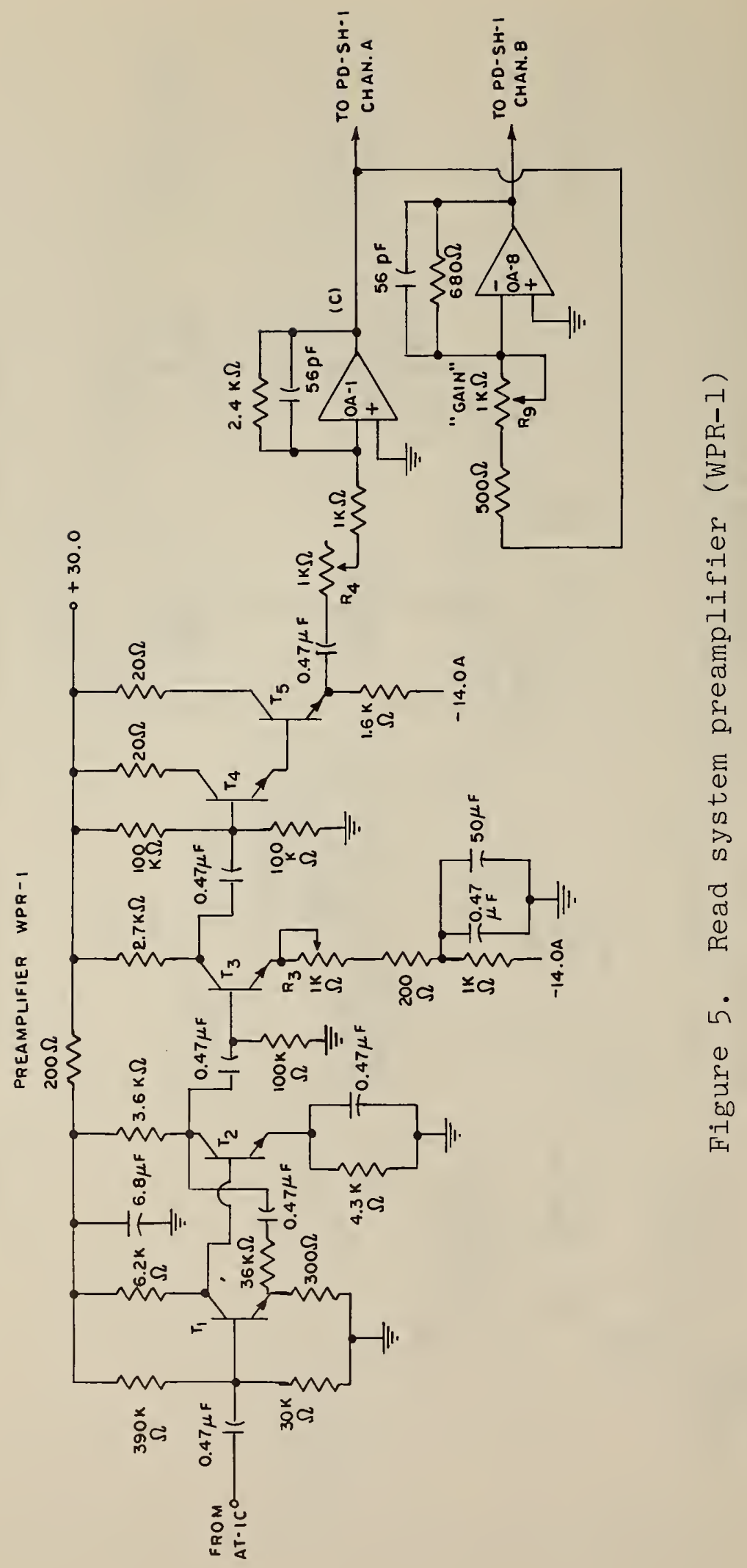




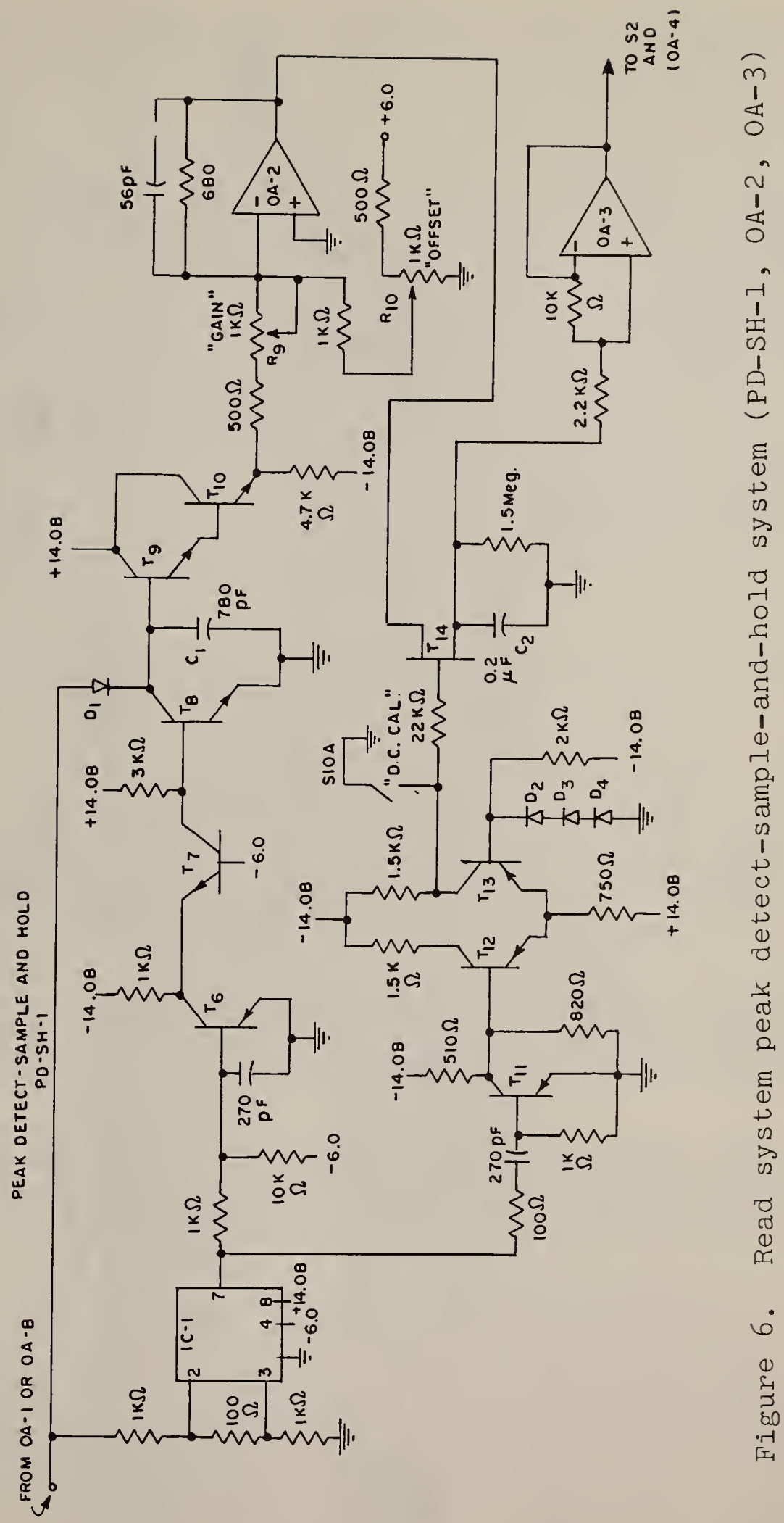




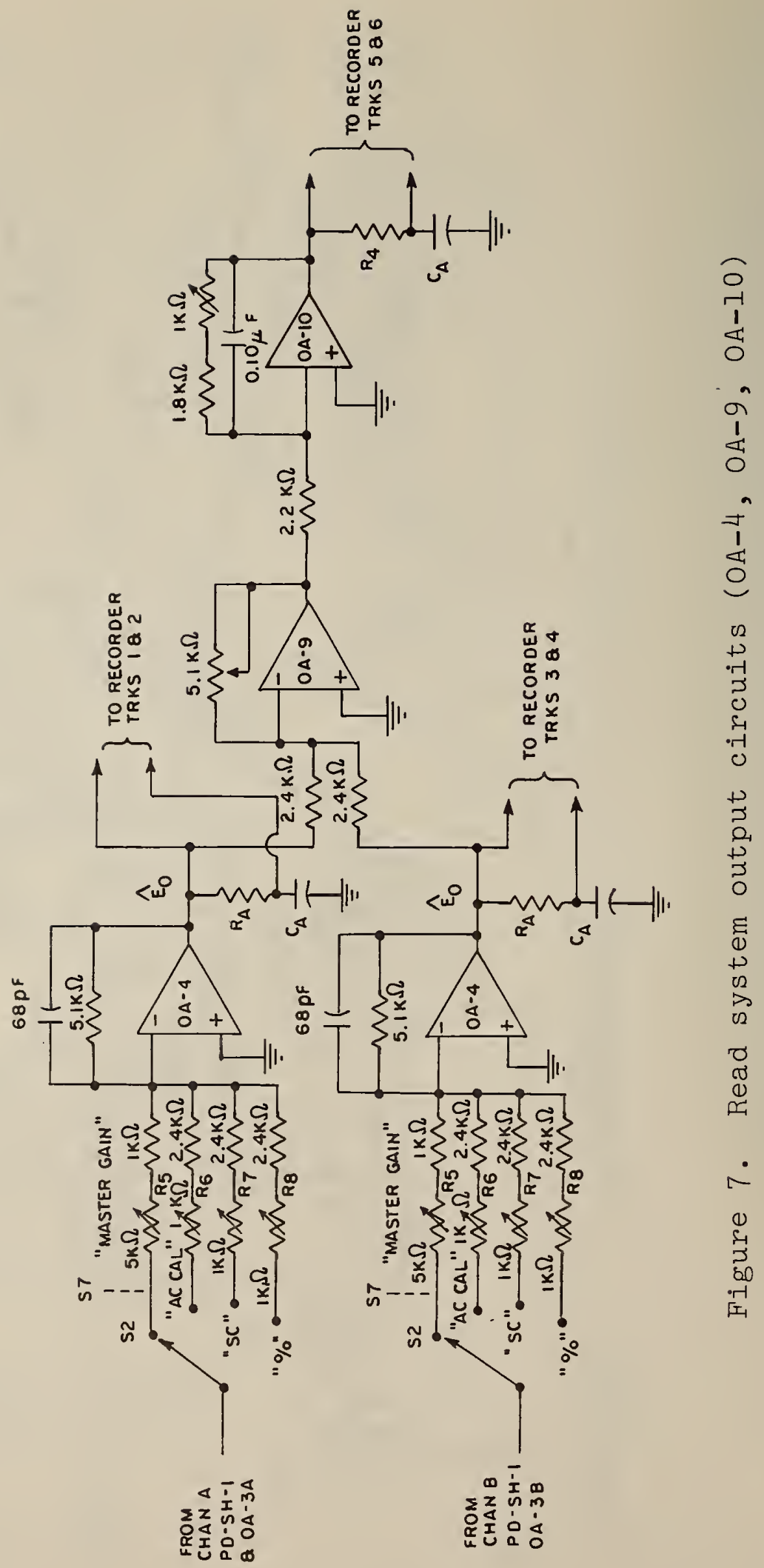


The hold capacitor $\mathrm{C}_{1}$ is charged to the positive signal peak value through diode $\bar{D}_{1}$. Simultaneously, the output signal from $O A-1$ is fed into the high-speed comparator integrated circuit IC-1. The output from IC-1 is a 4.0 volt $\mathrm{p} / \mathrm{p}$ pulse train whose widths are determined by the zero cross-over points of the signal. This pulse train is fed into the two network branches that are tied to the output of IC-1 at terminal 7. The pulses are integrated by capacitor $\mathrm{C}_{3}$ before driving the upper gating circuits consisting of $\mathrm{T}_{6}, \mathrm{~T}_{7}$ and $\mathrm{T}_{8}$. This integration stretches the signal peak voltage hold time across $C_{I}$, and therefore produces a sampling time margin. The sampling is initiated when the IC-l output pulse signal level falls from +4.0 volts towards ground and is differentiated at the input to $\mathrm{T}_{11}$. The differentiated signal triggers the $\mathrm{T}_{12}-\mathrm{T}_{13}$ current switching circuit and a strobe pulse is generated by $\mathrm{T}_{13}$ which drives the gate terminal of $\mathrm{T}_{14}$ (FET) during the stretched signal level interval. A de level now appears across $\mathrm{C}_{2}$ and is held there until another strobe pulse is initiated by the next signal cycle.

(b) The input circuits of the $O A-2 s$ are adjusted by $R_{9}$ and Rlo so that the dc levels from the PD-SH-ls will track their incoming signal peak values. Now see figure 7 .

(c) The output signal from each $\mathrm{C}_{2}$ is then fed into the OA-3's. The outputs from the $Q A-3^{\prime} \mathrm{s}$ are injected into their respective "MASTER GAIN" or "MG" branches of the final summing amplifiers OA-4. The MG potentiometers R5 are the principal calibration devices of the system. The signal is offset by the OA-4 "\% RANGE" branch roltage in order to attain the desired chart recorder percentage values.

(d) The output signal from each $\mathrm{OA}-4$ then is passed simultaneously to their respective chart recorder channels and to the second peak-to-peak summer amplifiers OA-9 where the outputs from each OA-4 are added together and then divided by 2 .

(e) The output from $O A-9$ is inverted by the unity gain amplifier OA-10. The output from OA-10 which represents the peak-to-peak signal level is fed into channels \#5 and \#6 of the chart recorder.

(f) A passive R-C averaging circuit is used to average the output signal from each $\mathrm{OA}-4$ and $\mathrm{OA}-10$. The voltage across the capacitor $C_{A}$ is applied to the chart recorder track that is adjacent to the signal peak track that it is averaging. The upper track of each pair on the chart is the average signal peak or average signal peak-to-peak track. 
The output summing amplifiers $O A-4$ circuits are very important ones in the measurement system. They have the following input lines which can be individually activated either by formalized switching system or by patch-cords (See figure 7):

\section{(1) "MASTER GAIN" (MG) $\mathrm{R}_{5}$ \\ (2) "AC CALIBRATE" ( $A C) \mathrm{R}_{6}$ \\ (3) "SET CHART" (SC) $\mathrm{R}_{7}$ \\ (4) "\% RANGE" (\%) $\mathrm{R}_{8}$}

$R_{6}, R_{7}$, and $R_{8}$ are adjusted so that the gain of $O A-4$ relative to dc inputs on these lines is equal to $G=1.667$. This gain converts the input signal amplitudes to output values that yield a direct relationship between the chart divisions and the percentage value of the signal under test.

The functions of these OA-4 inputs and adjustments are as follows:

(1) The "MASTER GAIN" potentiometer $R_{5}$ adjustment sets the final gain of the positive and negative peak reading channels so that they will produce the desired reference output level as provided by the NBS master cassette. The NBS secondary standard cassette tapes will then be calibrated with respect to this level. The "MG" input branch to OA-4 functions during the normal operating mode.

(2) The "AC CALIBRATE" input to OA-4 switches in a simulating ac signal to test the stability and adjustment of the system at any time.

(3) The "SET CHART" input to OA-4 is switched in during the "SET CHART" mode of operation. In this mode 3.000 volts dc is injected into OA-4 and produces the output voltage level of 1.25 volts dc which is used when setting the chart recording devices into their $100 \%$ reference states prior to recording and calibration.

(4) The "\%" input to OA-4 affects each of the preceding modes by providing a controlled offset voltage. This offset voltage is adjusted with the calibrated 10 turn potentiometer $R_{12}$ so that the signal output from $O A-4$ will consist of a desired percentage of the total signal range. For example, a range consisting of from $50 \%$ to $150 \%$ of the total signal amplitude is charted on a strip chart recorder 
by offsetting the lower $50 \%$ of the output signal and then selecting that chart recorder range that will encompass the next $100 \%$ of the total signal level over its limits.

An NBS chart recorder track has a useful width of 10 major linear divisions as shown in figure 17 . When the recorder sensitivity is set to $0.50 \mathrm{v} / \mathrm{div}$ then full chart deflection is obtained with 5.000 volts dc. If the chart centerline is chosen and "SET" as the 100\% reference level then 1.250 volts de output from OA-4 or OA-10 will produce a trace at this level as previously indicated. Since 3.000 volts dc into OA-4 represents the 100\% signal level for the system, it is necessary to offset this by inserting 2.250 volts dc onto the "\%" line. This results in an OA-4 output equal to 0.750 volts times the $O A-4$ gain of $G=1.667$ or 1.250 volts during the "SET CHART" (S2) mode of operation. The bottom of the chart then represents the $50 \%$ signal level and the top of the chart represents the $150 \%$ signal level.

When an actual cassette signal produces $1.250 \mathrm{v}$ dc output from an OA-4 stage, then the recorder channel which is driven by that stage will produce a trace at the $100 \%$ chart centerline. As previously stated, recorder tracks \#l through \#4 display the zero-to-peak signal level responses and their average values.

(5) The peak-to-peak chart recording is produced by the output from the OA-9 - OA-10 combination. In "SET CHART" operation each OA-4 feeds $1.25 \mathrm{v}$ dc into the summer OA-9. Since each input of $O A-9$ is adjusted for a gain of $G=0.50$, therefore, its output is also equal to $1.250 \mathrm{v}$ dc. Unity gain inverter OA-10 then drives channels 5 and 6 to their centerline (100\%)position. The same situation now obtains when the OA-4's are driven by a signal which is reproduced from a cassette. An example of the actual cassette measurement operation of the system after it has been $\mathrm{ac}$ and $\mathrm{dc}$ calibrated is as follows:

(a) The NBS master cassette is run on the measurement system and since the positive and negative peaks (zero-topeak) are assumed to be $100 \%$ values when derived from the master tape, the "MASTER GAIN" controls are set to produce $1.250 \mathrm{v}$ dc output from each of the two OA-4's. This will produce a trace at the centerline of each of the six chart recorder tracks.

(b) The candidate cassettes are now run on the calibrated system and their relative zero-to-peak and peak-topeak percentages will be charted. For example, if a candidate tape cassette charts $100 \%$ positive peak amplitudes on channels \#3 and \#4 and 50\% negative peak amplitudes on 
channels \#l and \#2 it will chart peak-to-peak amplitude at the $75 \%$ level on channels $\# 5$ and \#6. In other words the candidate cassette has a peak-to-peak signal amplitude which is 150 or $75 \%$ relative to the "master" reference level.

\section{EXPERIMENTAL RESULTS}

\subsection{Case Histories of Submitted Cassette Transports}

The field of digital cassette transport design is relatively new and many of the manufacturers have little background in the development of this type of product. This makes it difficult to find reference cassette transports at the present state-of-the-art. All of the data which are presented in section 5 were produced from 6 transports that could be put into operation.

Some of the typical problems which were encountered among the test cassette transports were as follows: 1

(a) Guidance defects which led to tape damage.

(b) Defects in the speed control systems which caused instability.

(c) Electronic system defects resulting in burnt components and blown fuses.

(d) Mechanical defects in the driving motors.

5.2 Cassette Transports Used for Test Measurements

(1) Only 6 of the 8 cassette recorders which were tested were used to produce the data which are described in this section. These are recorders numbered 1, 4, 5, 6, 7 and 8. Although there are numerous options available with each recorder, the following information relates only to the models that were used by NBS:

Unit \#I (Dual Capstan)

(a) Capstan motor: One printed circuit dc motor for

(b) Reel motor: all functions ( 4 belts).

${ }^{1}$ In some instances the defects were able to be corrected and the transports were used for the tests described in section 5.3 . 
(c) Motor speed: SIow 6 ips (forward and reverse) Fast 80 ips (forward and reverse)

(d) Speed stability: Company claims: 3\% S.T.; $2 \%$ L.T.* NBS measurements: see figure 8.

(e) Head: Single track - dual gap.

(f) Miscellaneous: Has write circuits (phase encode) which needs external driving source. Read amplifier outputs are analog. Read-while-write capability. Produced for OEM and in-house use.

Unit \#4 (Dual Capstan)

(a) Capstan motor: one dc with Hall generator feedback control.

(b) Reel motors: two dc with Hall generator feedback control.

(c) Motor speed: Slow 7.5 ips (forward and reverse) Fast 40-400 ips (forward and reverse)

(d) Speed stability: company claims 4\% S.T.; +2.5\% L.T. NBS measurement: see figure 8 .

(e) Head: 2 track - single gap (standard)**

(f) Miscellaneous: No read or write circuit with NBS unit. Produced for OEM use.

Unit \#5 (Single Capstan)

(a) Capstan motor: one ac synchronous

(b) Reel motor: two dc servo controlled (belt drive)

(c) Motor speed: Slow 5 ips (forward and reverse) Fast 120 ips (forward and reverse)

(d) Speed stability: No company information. NBS measurements: see figure 8. *"S.T." and "J.T." mean "short term" and "long term" speed variations respectively.

**A "standard" head indicates that both gaps are of equal width. 
(e) Head: 2 track - single gap (non-standard: different track widths)

(f) Miscellaneous: Has write circuits (phase encode) which need external driving source. Has analog output read amplifiers. Produced for OEM and in-house use.

Unit \#6 (Dual Capstan)

(a) Capstan motor: one dc servo controlled.

(b) Reel motor: two de torque.

(c) Motor speed: Slow 7.5 ips (forward and reverse). Fast 90 ips (reverse).

(d) Speed stability: Company claims: 3\% S.T., $\pm 3 \%$ L.T. NBS measurements: see figure 9.

(e) Head: 2 track - dual gap (standard). Write current $8.0 \mathrm{~mA}$.

(f) Miscellaneous: Has write circuits (phase encode) which needs external driving source. Has analog output read amplifiers. Produced for OEM use. Read-whilewrite capability.

Unit \#7 (Single Capstan Type)

(a) Capstan motor: one bidirectional servo controlled.

(b) Reel motors: two dc torque (direct drive).

(c) Motor speed: Slow 12.5 ips (forward and reverse) Fast 120 ips (forward and reverse)

(d) Speed stability: No company information NBS measurements: see figure 9.

(e) Head: 2 track - single gap (standard). Write current $5.0 \mathrm{~mA}$.

(f) Miscellaneous: Has write circuits (phase encode) which need external drive source. Has analog output read amplifiers. Produced for OEM and in-house use. Needs separarate external generator for servo loop control 
Unit \#8 (Dual Capstan)

(a) Capstan motor: Two hysteresis synchronous.

(b) Reel motors: Two dc torque (direct drive).

(c) Motor speed: Slow 8 ips (forward and reverse).

(d) Speed stability: Company claims 4\% S.T., 0.5\% L.T. NBS measurement: see figure 9.

(e) Head: 2 track - single gap (standard). Write current $5.25 \mathrm{~mA}$.

(f) Miscellaneous: Has write circuits (phase encode) which needs external driving source. Read amplifier outputs are analog or shaped. Produced for OEM use.

(2) The cassette recorder speed stability data in figures 8 and 9 were all produced with a test tape which was accurately recorded at 1600 frpi. The signal frequency output from the recorder was measured on a frequency counter and was plotted as a function of the "Time in Minutes from the BOT". Note that the machine speed can be determined from:

$$
\text { Machine speed }(\text { in } / \mathrm{s})=\frac{\text { Measured frequency }}{800}
$$

For example the speed of cassette transport \#4 is equal to:

$$
\frac{\text { Measured frequency }}{800}=\frac{6000}{800}=7.5 \mathrm{in} / \mathrm{s} \text { (ips) }
$$

This is the rated machine speed for this \#4 transport; it is achieved only for a small time interval at approximately 0.7 minutes from the BOT. At all other times, the machine speed deviates from this nominal value. Note that the curves in figures 8 and 9 terminate at different times due to the variation in the average recorder speeds.

Figures 10 and 11 display the tension which is exerted on the cassette tape by the take-up reels of the recorders in the figures. Recorder \#6 is not shown in the figures which are drawn in terms of the "Tape Tension in Grams versus the Time in Minutes from the BOT". The measurements were performed on an ITC M-100 Tension Monitor with the tapes running in the forward direction. 


\subsection{Experimental Measurement Data}

The six cassette transports which were described in the previous paragraph were used to perform a series of signal amplitude measurements on a sample of 20 tape cassettes. These cassettes were chosen from a pool of 44 tapes which were obtained from 9 sources and are identified in the tables with a letter and number designation.

(1) Table 1 gives the base and oxide coating thickness dimensions for the 20 test cassettes.

(2) Table 2 gives the pressure pad dimensions and the pad materials used in the 20 test cassettes.

(3) Table 3 gives the coercitivity $\mathrm{H}_{c}$, the residual flux $\phi_{r}$ and the squareness ratio of the test cassette tapes. Figure 19 shows the hysteresis loops for four of the cassettes; C9, Cl3, Fl and G3. C9 is chromium dioxide tape whose output was above $150 \%$ of the average level and was not included in the 20 tape samples.

(4) Tables $4 \mathrm{~A}$ and $4 \mathrm{~B}$ give the 300 signal amplitude measurement results relative to the $100 \%$ level set by the interim "master level" tape Cl3. The histograms in figures 12 to 15 are derived from these tabulated data.

(5) Table 5 gives the average, the median, the mode and the standard deviation of the 300 signal amplitude measurements. The data is broken down into groups of runs: $1-6,7-12$, and $13-15$ as well as the full run of $1-15$.

(6) Table 6 denotes which cassette transport was used for recording and reproducing the signal during each of the 15 runs.

Figure 12 is a group of curves which show the results of a cassette torque test which was performed on the 20 test cassettes using the ITC M-200 Torque Tester. Although all of the cassettes are not displayed in these curves the upper and lower limit curves are shown. Note that $8 \mathrm{~g}-\mathrm{cm}$ of holdback torque was applied during the tests.

The signal amplitude test procedures were as follows:

(1) The 20 test cassettes were ac (60 Hz) bulk erased.

(2) A pulse train consisting of all l's was then recorded on each of the test tape cassettes at 1600 flux reversals per inch. Only 3 of the six test transports were used for recording purposes: transports numbered 6, 7 and 8 . These 
Table 1. Test cassette tape dimensions

\begin{tabular}{|c|c|c|c|c|}
\hline TAPE & BASE & NESS & COATING & CKNESS \\
\hline & $\mu \mathrm{m}^{\mathrm{b}}$ & $\underline{\mu i n} b$ & $\underline{\mu m}$ & $\mu i n$ \\
\hline A 4 & 12.4 & 490 & 6.85 & 270 \\
\hline BI & 13.8 & 545 & $5.71-5.84$ & $225-230$ \\
\hline B3 & 14.1 & 555 & $5.20-5.58$ & $205-220$ \\
\hline $\mathrm{Cl}$ & 12.4 & 490 & $6.59-6.85$ & $260-270$ \\
\hline $\mathrm{C} 2$ & 12.2 & 480 & $6.59-6.73$ & $260-265$ \\
\hline C3 & 12.2 & 480 & 7.10 & 280 \\
\hline $\mathrm{C} 8$ & 12.7 & 500 & $6.09-6.22$ & $240-245$ \\
\hline $\mathrm{Cl} 3$ & 14.0 & 550 & $5.32-5.84$ & $210-230$ \\
\hline D6 & 11.2 & 440 & 6.73 & 265 \\
\hline D8 & 10.7 & 420 & $6.59-7.36$ & $260-290$ \\
\hline E6 & 12.4 & 490 & $5.46-5.84$ & $215-230$ \\
\hline E7 & 12.6 & 495 & 5.46 & 215 \\
\hline FI & 11.2 & 440 & $5.58-5.87$ & $220-230$ \\
\hline F8 & 12.9 & 510 & $5.84-6.59$ & $230-260$ \\
\hline F9 & 12.4 & 490 & 6.59 & 260 \\
\hline F15 & 12.9 & 510 & 6.59 & 260 \\
\hline G3 & 11.4 & 450 & $6.87-7.36$ & $270-290$ \\
\hline G4 & 11.9 & 470 & $6.59-6.85$ & $260-270$ \\
\hline $\mathrm{JI}$ & $12 \cdot 3$ & 485 & $5.46-5.71$ & $215-225$ \\
\hline SI & 11.2 & 440 & $4.69-5.07$ & $184-200$ \\
\hline
\end{tabular}

an tables 1,2 and 3 the data are given in terms of the SI units followed by the equivalent English units in the column to the right.

$\mathrm{b}_{\mu \text { in }}=$ microinches

$\mu \mathrm{m}=$ micrometer $(1 \mu \mathrm{m}=39.4 \mu$ in $)$ 
Table 2. Test cassettes pressure pad dimensions and materials

\begin{tabular}{|c|c|c|c|c|c|}
\hline \multirow[b]{2}{*}{ TAPE } & \multicolumn{2}{|c|}{ PAD LENGTH } & \multicolumn{2}{|c|}{ PAD WIDTH } & \multirow[b]{2}{*}{ PAD MATERIALS } \\
\hline & $\underline{m m}$ & in & $\underline{\mathrm{mm}}$ & in & \\
\hline A 4 & 5.33 & 0.21 & 7.62 & 0.30 & Felt on Foam Rubber \\
\hline $\mathrm{Bl}$ & 3.81 & 0.15 & 5.59 & 0.22 & Felt on Spring \\
\hline B3 & 3.81 & 0.15 & 5.59 & 0.22 & Felt on Spring \\
\hline $\mathrm{Cl}$ & 4.32 & 0.17 & 6.10 & 0.24 & Felt on Spring \\
\hline $\mathrm{C} 2$ & $4 \cdot 32$ & 0.17 & 6.86 & 0.27 & Felt on Spring \\
\hline C3 & $4 \cdot 32$ & 0.17 & 6.86 & 0.27 & Felt on Spring \\
\hline $\mathrm{C} 8$ & 5.84 & 0.23 & 9.40 & 0.37 & Felt on Foam Rubber \\
\hline $\mathrm{C} 13$ & 6.86 & 0.27 & 9.40 & 0.37 & Cloth on Foam Rubber \\
\hline D6 & 3.30 & 0.13 & 5.33 & 0.21 & Felt on Spring \\
\hline D8 & $3 \cdot 30$ & 0.13 & 5.33 & 0.21 & Felt on Spring \\
\hline E6 & 8.64 & 0.34 & 8.38 & 0.33 & Plastic Sheet on Foam Rubber \\
\hline E7 & 8.64 & 0.34 & 8.38 & 0.33 & Plastic Sheet on Foam Rubber \\
\hline $\mathrm{F} 1$ & 4.32 & 0.17 & 5.84 & 0.23 & Felt on spring \\
\hline F8 & 6.10 & 0.24 & 8.64 & 0.34 & Felt on Foam Rubber \\
\hline F9 & 6.10 & 0.24 & 8.89 & 0.35 & Felt on Foam Rubber \\
\hline F15 & 6.10 & 0.24 & 8.89 & 0.35 & Felt on Foam Rubber \\
\hline G3 & 6.60 & 0.26 & 5.59 & 0.22 & Felt on spring \\
\hline G4 & 6.60 & 0.26 & 5.59 & 0.22 & Felt on Spring \\
\hline J1 & 7.87 & 0.31 & 7.87 & 0.31 & Felt on Spring \\
\hline SI & 4.32 & 0.17 & 5.59 & 0.22 & Felt on Spring \\
\hline
\end{tabular}


Table 3. Magnetic characteristics of test cassette tapes

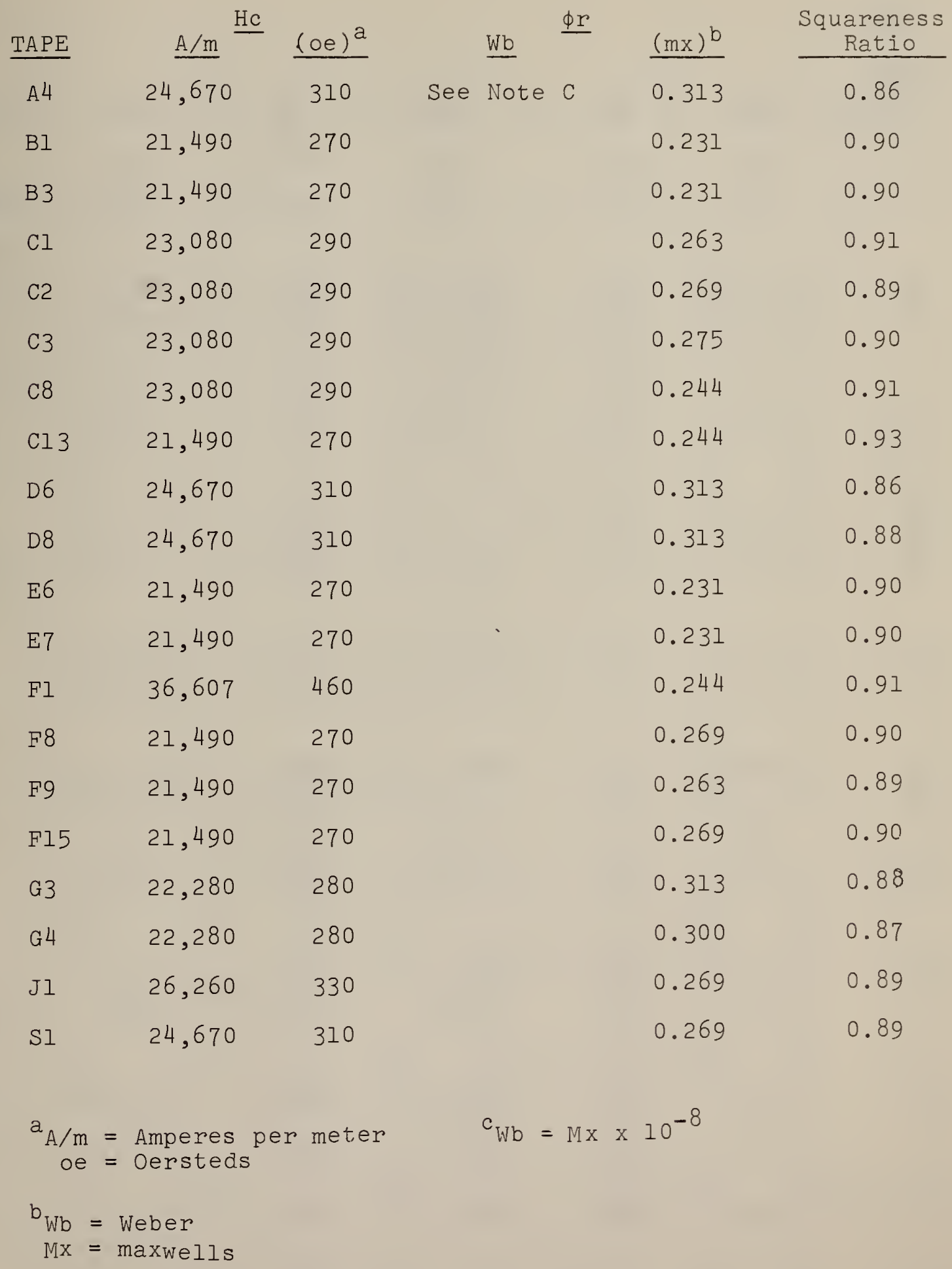


Table 4a. Signal amplitude response of the 20 test cassettes

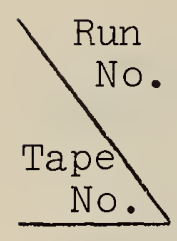

BI

B3

C1

$\mathrm{C} 2$

C3

C8

$\mathrm{C} 13^{\mathrm{a}}$

D6

D8

E6

E7

F1
F8
F9

F15

G3

G4

JI

J2

SI
129

2

101.3

100

104

99

102

99

100

129

124

97

94

128

89

94

97

103

101.3

127

125

126

124

128

102

102

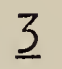

93.5

100

112.5

101.5

109.5

105.5

100

133

125.5

106.5

94.5

130.5

95

108.5

104

105.5

103.5

137.5

131.5

131.5

129.5

127.5

97.5

94.5

121.5

91.5

100.5

86

101.5

103.5

125.5 $\underline{5}$

101.8

98.5

98.5

100

95.5

96.5

100

126.5

119

125.5

131

126.5

128.5

a

C13 is the "master" tape. 
Table 4b. Signal amplitude response of the 20 test cassettes

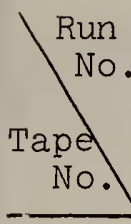

BI

B2

$\begin{array}{lrrlrlllll}\text { C1 } & 98 & 99 & 99.5 & 100 & 100 & 112 & 99 & 102 & 99 \\ \text { C2 } & 107 & 104 & 102 & 98 & 102 & 100 & 101 & 102 & 100.5 \\ \text { C3 } & 97 & 100 & 100.5 & 100 & 103.5 & 108 & 102 & 100 & 102.5 \\ \text { C8 } & 965 & 96 & 101.5 & 107 & 102 & 106 & 102 & 102.5 & 99.5 \\ \text { C13 } & 100 & 100 & 100 & 100 & 100 & 100 & 100 & 100 & 100\end{array}$

D6

$121 \quad 126$

$121.5 \quad 125$

$124.5 \quad 125.5$

124 125

$121.5 \quad 117$

$128.0 \quad 124$

122

127.5

D8

$121 \quad 123$

120 120.5

$102 \quad 100$

101.599

104

118 $99.5 \quad 100 \quad 100$

111.596

E7

$98 \quad 100$

$$
101.5 \quad 108
$$

$110.5 \quad 103.5 \quad 103$

$110 \quad 100$

$$
91.5 \quad 105 \quad 107
$$

117

102

$97.5 \quad 108$

110.5

$121.5 \quad 102$

108 100

102

$97.5 \quad 92.5$

$$
95.5 \quad 110
$$

G

$$
105
$$

$$
102
$$

106

112

112

$120.5 \quad 108$

112

121

110

110

110.5

$\begin{array}{llll}110 & 112 & 109.5 & 116\end{array}$

$\begin{array}{llll}125 & 126 & 120.5 & 125\end{array}$

131

$140.5 \quad 124$ 121

$136.5 \quad 121$

$120.5 \quad 124.5$

J2

125

$\begin{array}{lll}125.5 & 121.5 & 129\end{array}$ 
Table 5. Cassette transports used for each run

Test

Run No. Recorded on Transport No.

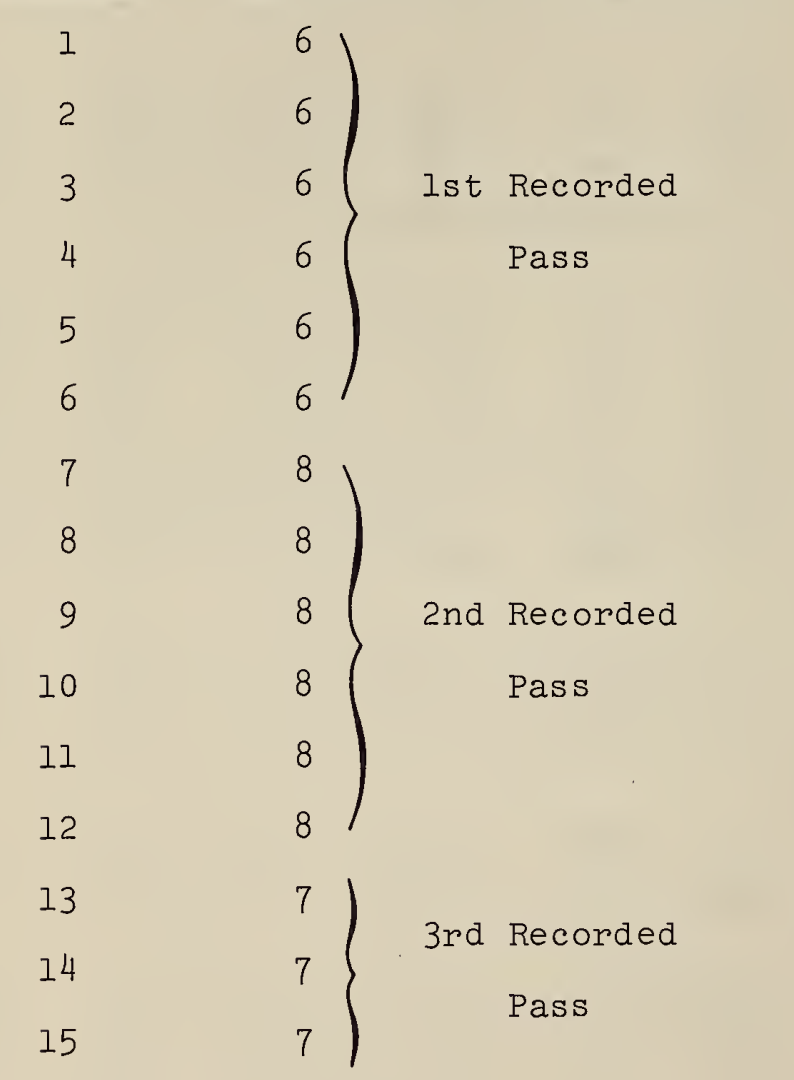

Reproduced on Transport No. 
Table 6. Statistical data derived from the 15 runs

\begin{tabular}{|c|c|c|c|c|}
\hline RUNS & $\begin{array}{l}\text { AVEPAGE } \\
\text { VALUES } \\
\end{array}$ & $\begin{array}{l}\text { MEDIAN } \\
\text { VALUES } \\
\end{array}$ & $\begin{array}{c}\text { ABSOLUTE } \\
\text { NODES } \\
\end{array}$ & $\begin{array}{l}\text { STANDARD } \\
\text { DEVIATION } \\
\end{array}$ \\
\hline $1-6$ (LOW) & 98.7 & 99.3 & 100.0 & 5.11 \\
\hline $1-6(\mathrm{HIGH})$ & 127.6 & 127.5 & $x^{a}$ & 3.90 \\
\hline $1-6$ (ALL) & 107.3 & 101.5 & 100.0 & $\mathrm{X}$ \\
\hline $7-12$ (LOW) & 102.1 & 100.0 & 100.0 & 5.05 \\
\hline $7-12(\mathrm{HIGH})$ & 124.9 & 124.8 & $\mathrm{X}$ & 5.82 \\
\hline 7-12 (ALL) & 108.9 & 104.5 & 100.0 & $X$ \\
\hline $13-15$ (LOW) & 101.3 & 100.0 & 102.0 & 4.54 \\
\hline $13-15$ ( $\mathrm{HIGH})$ & 123.0 & 122.5 & 124 & 2.03 \\
\hline $13-15$ (ALL) & 106.7 & 102.0 & 100.0 & $\mathrm{X}$ \\
\hline $1-15$ (LOW) & 100.6 & 100 & 100 & 5.2 \\
\hline $1-15$ ( $\mathrm{HIGH})$ & 125.7 & 125.0 & 125.0 & 4.88 \\
\hline $1-15$ (ALL) & 107.9 & 102.0 & 100.0 & $\mathrm{X}$ \\
\hline
\end{tabular}

$a=d i d n^{\prime} t$ calculate

b "Computed standard deviation". Data processed by William B. Truitt 


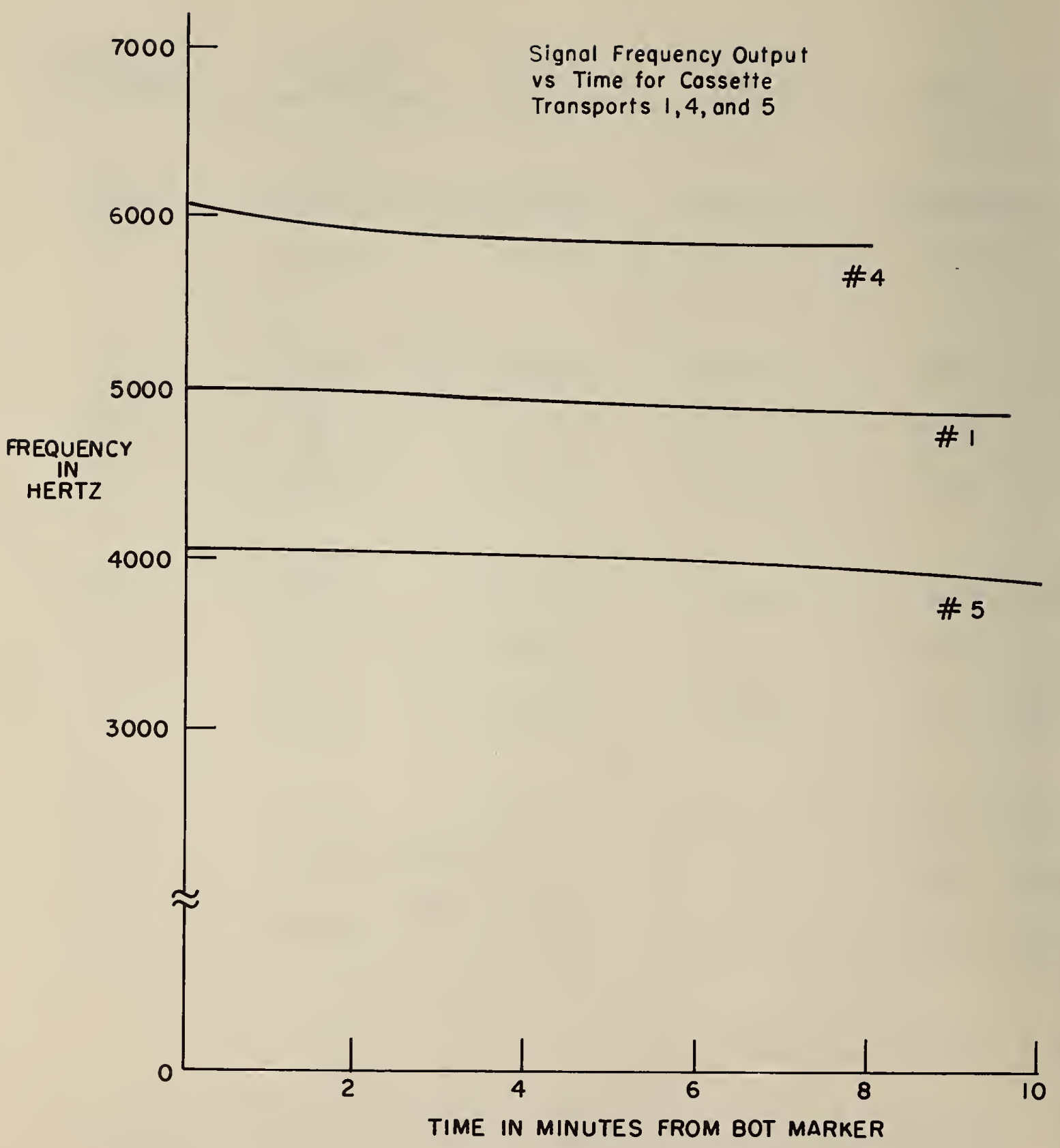

Figure 8. Cassette transport speed measurement curves 


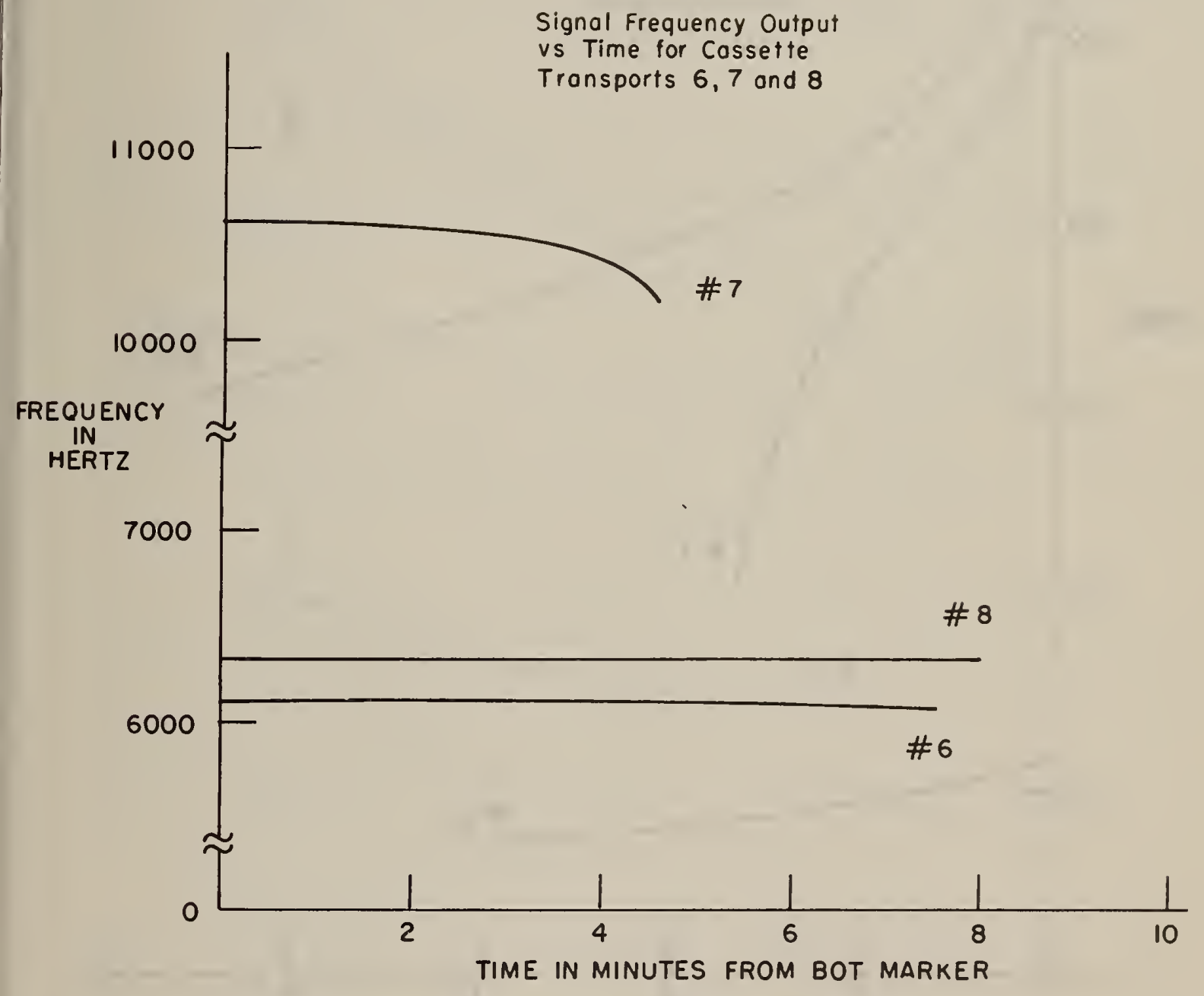

Figure 9. Cassette transport speed measurement curves 


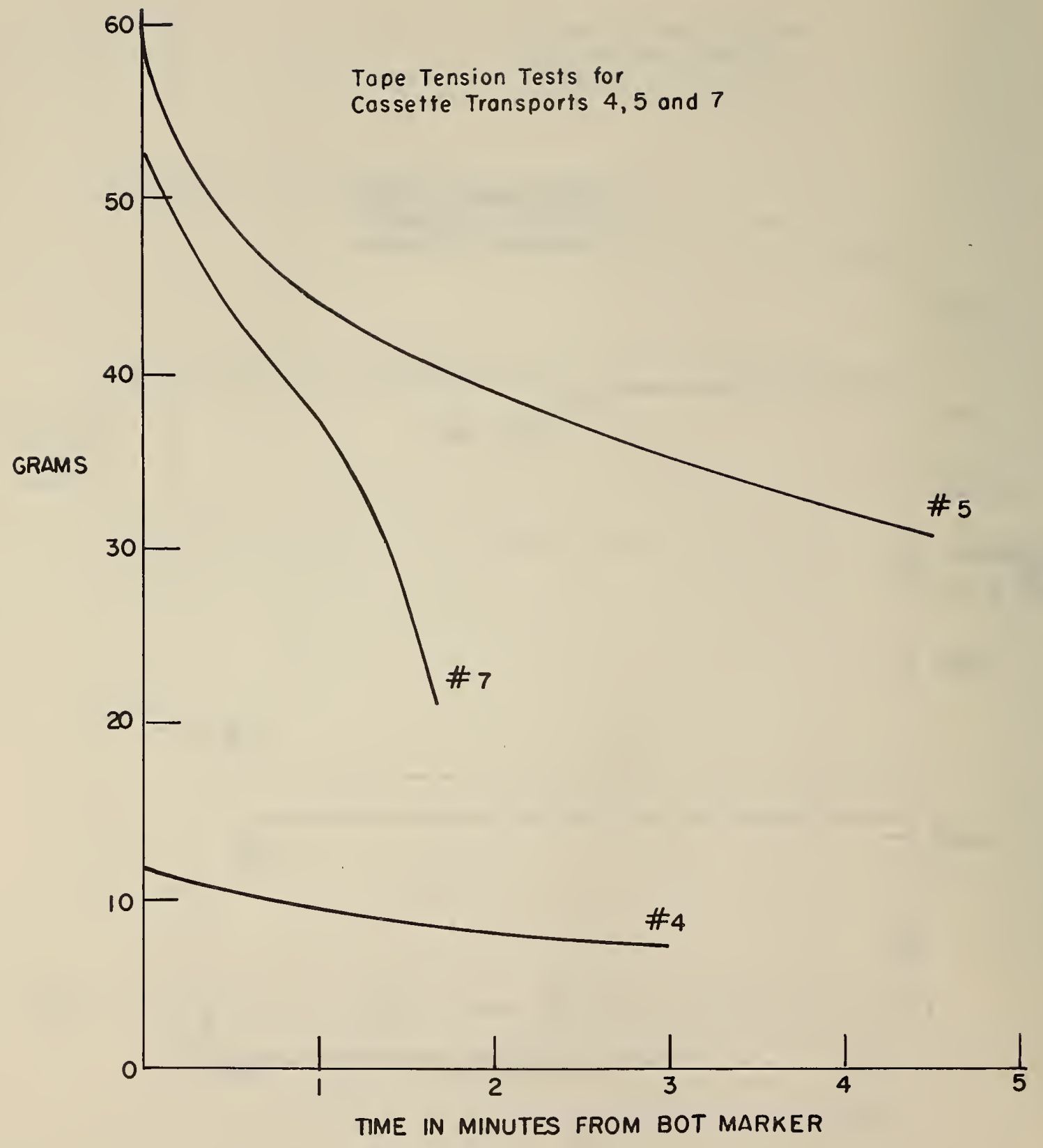

Figure 10. Tape tension test curves 


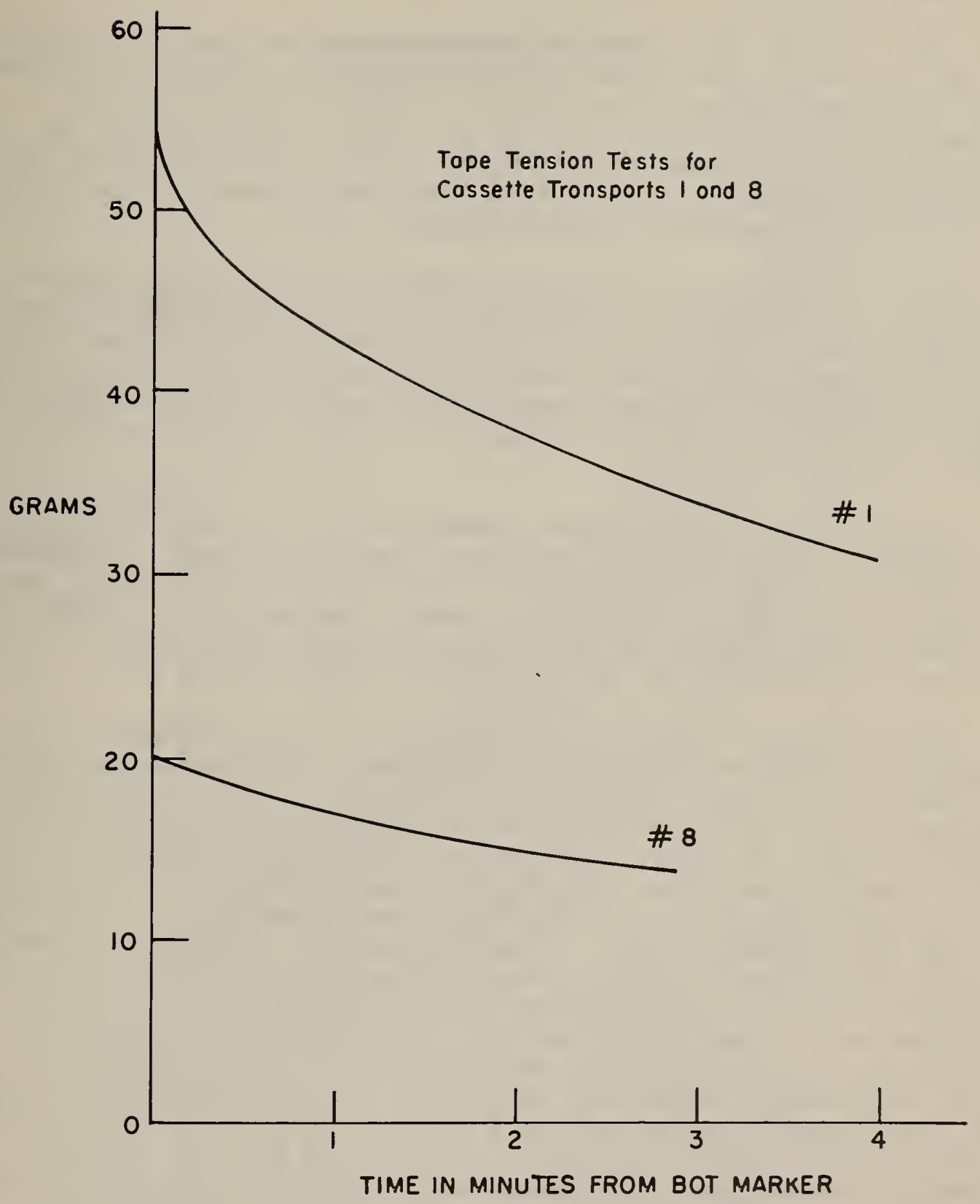

Figure 11. Tape tension test curves 
were the only units which were received with operative write circuits. The continuously controlled NBS write system has not yet been developed since the reference transducers have not been determined at this time.

(3) After each of the 20 cassettes had been recorded on one of these 3 machines their recorded signal amplitudes were measured (after the fourth or later pass) on the system as described in section 4. This resulted in 120 measurements for each of the first two recorded passes and for 60 measurements on the third recorded pass for a total of 300 signal amplitude measurements.

(4) There was no de facto signal amplitude "master" cassette available for calibrating the measurement system on the first run; therefore the system was set up close to its operating center and was gradually readjusted until the general dispersion of signal amplitudes were all contained within the chart recorder range: in this case from $50 \%$ to $150 \%$.

After this first coarse measurement run was completed, the numerical data were organized and evaluated. Cassette Cl3 was found to be centrally located and was assigned the position of temporary "master level" cassette. As such, it was used during each run to calibrate the measurement system to the "100\% level" as described in section 4.

The results of the 300 signal level measurements are compiled in Tables $4 \mathrm{a}$ and $4 \mathrm{~b}$ in terms of percentages relative to the "100\% level" established by $\mathrm{Cl} 3$ and the histograms in figures 13 to 16 were based on the data in these tables. The abscissae of these histograms are plotted in terms of the "\% variations from the 100\% master level". For example, $+5 \%$ is equivalent to a $105 \%$ signal amplitude level relative to the $100 \%$ master level. The histogram in figure 13 shows the distribution of signal amplitudes for the accumulated results of all 3 recording runs consisting of a total of 300 samples. The histograms in figure 14 to 16 are the results of the individual recording runs, i.e., figure 14 shows the signal amplitude distribution which results from 120 measurements made on the 6 test transports after the 20 cassettes had been recorded on transport No. 6. Figure 15 and 16 shows the histograms which resulted from the runs which were based upon the recordings made on transports numbered 8 and 7 respectively. Note that in every instance the absolute modal value is at "0\% deviation from the $100 \%$ master level" while relative modal values occur 20 to $25 \%$ above this level. That is, there is a trend towards relative signal amplitude classes which are approximately $25 \%$ apart. 


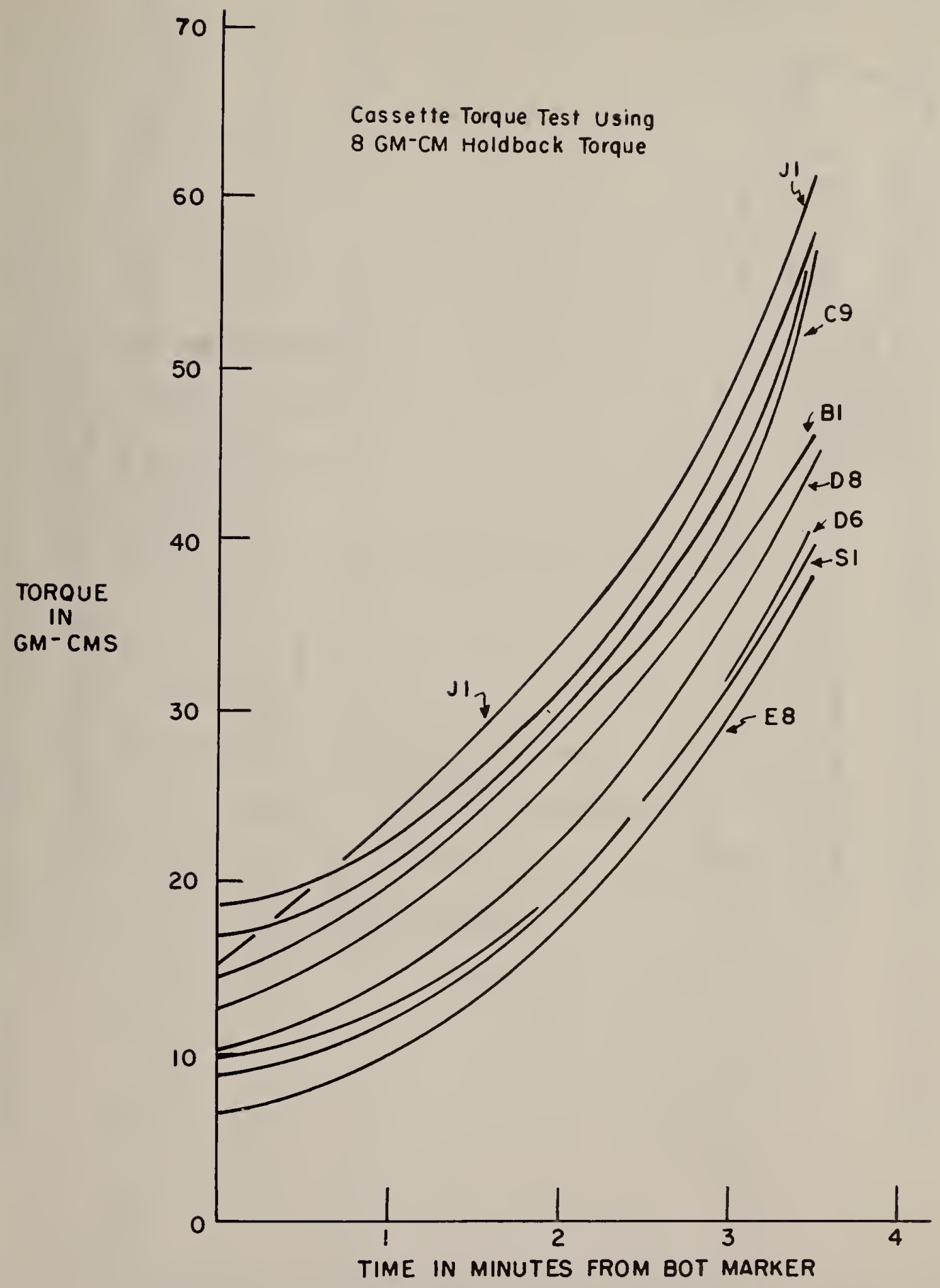

Figure 12. Cassette torque test curves 


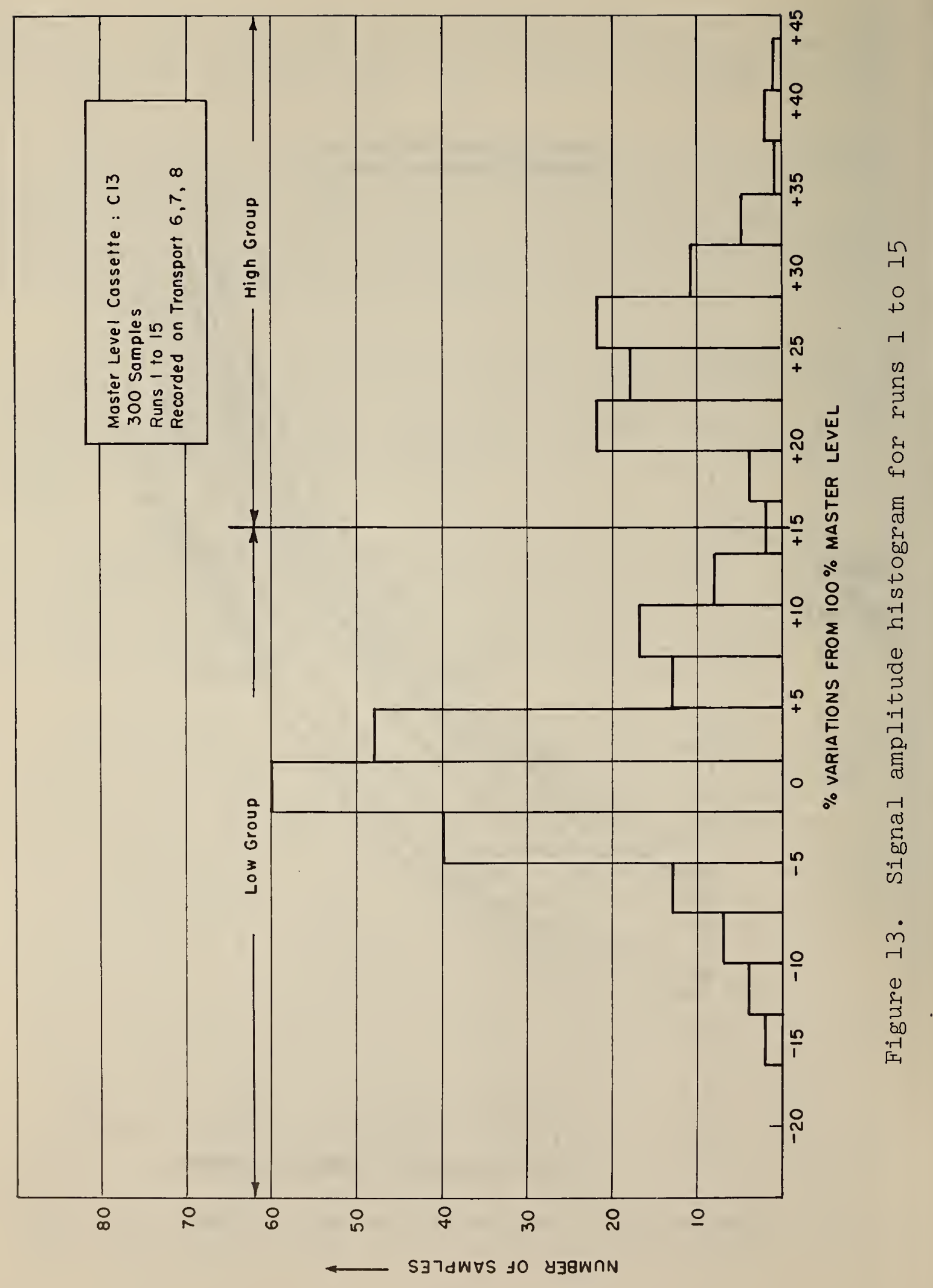




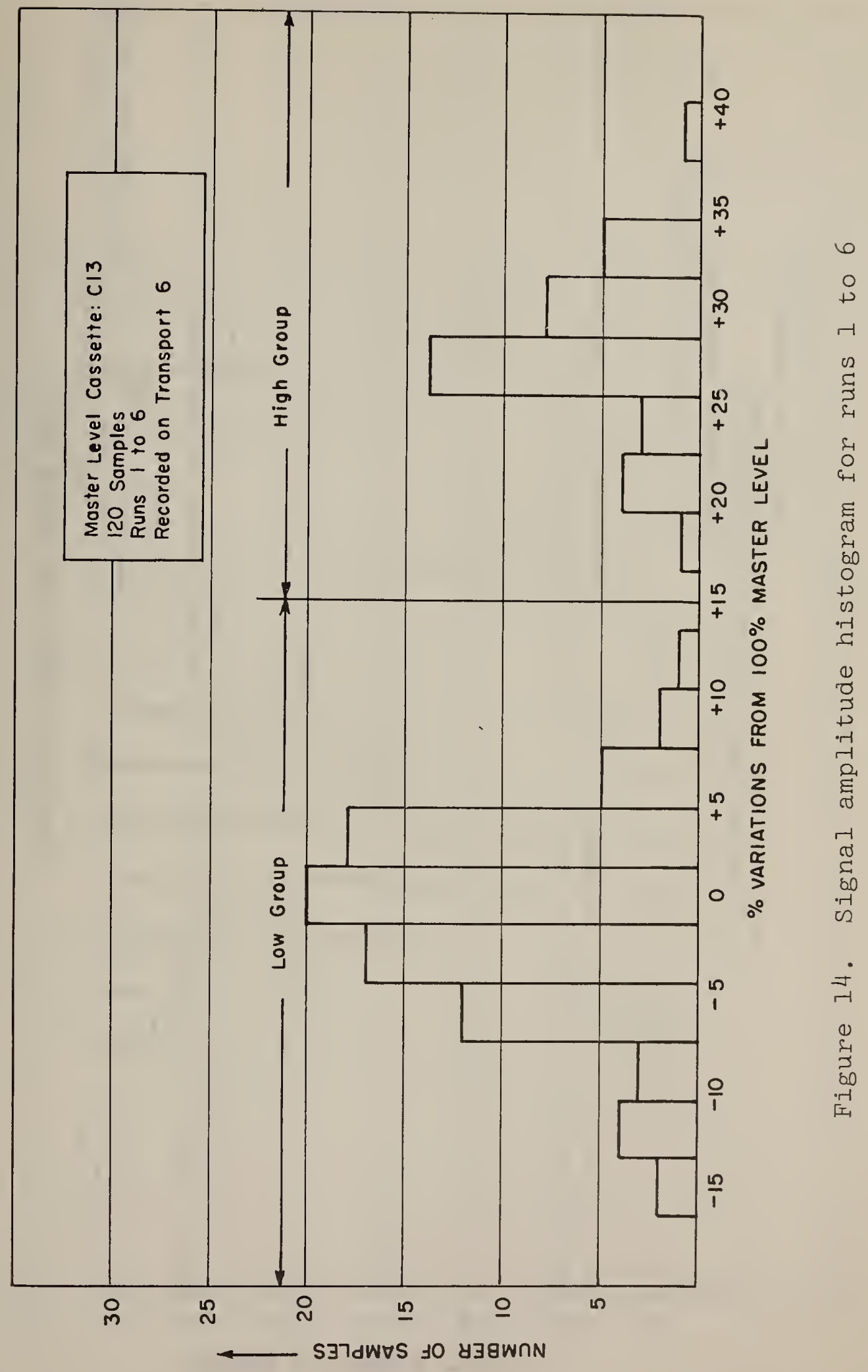




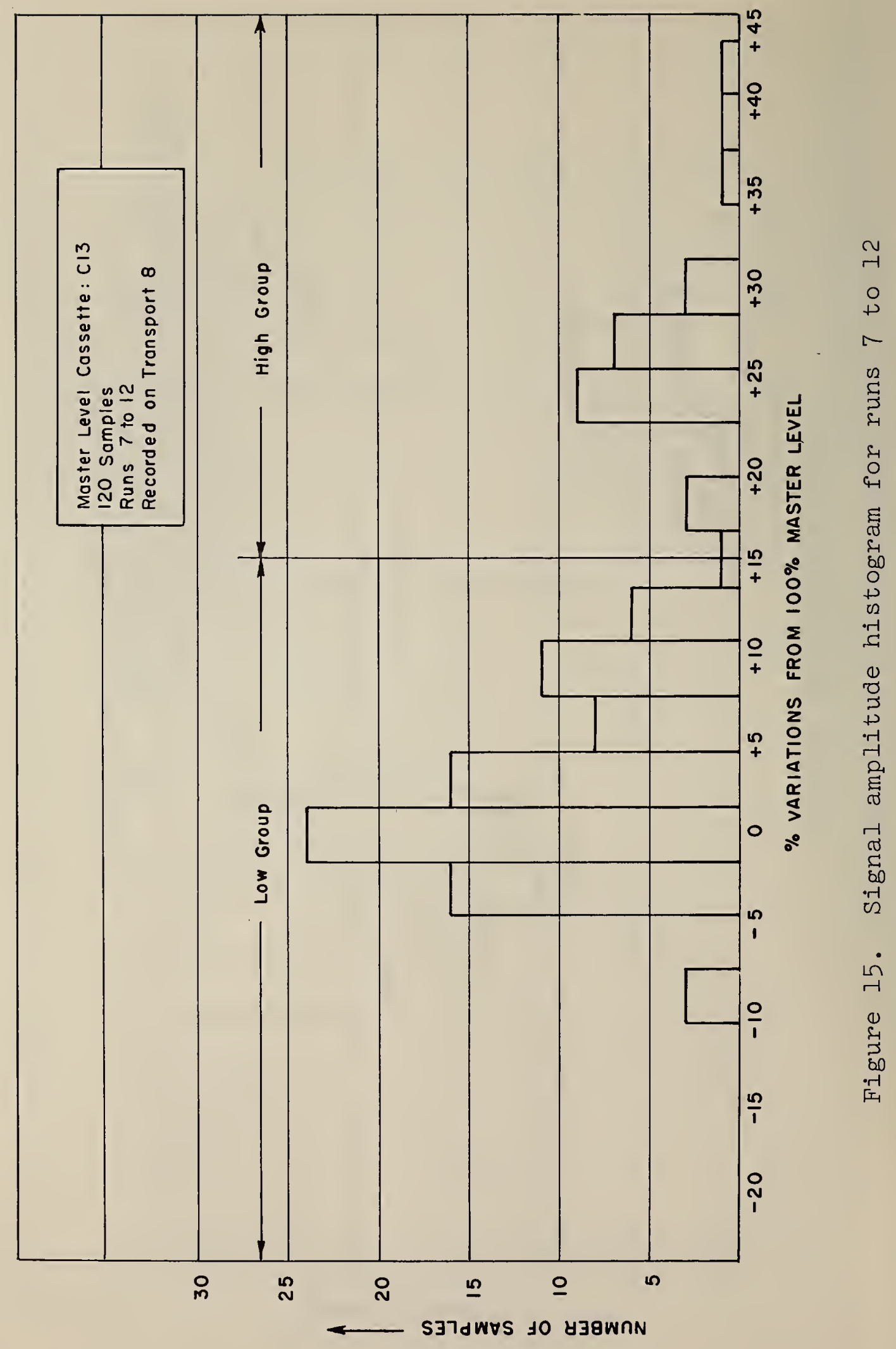




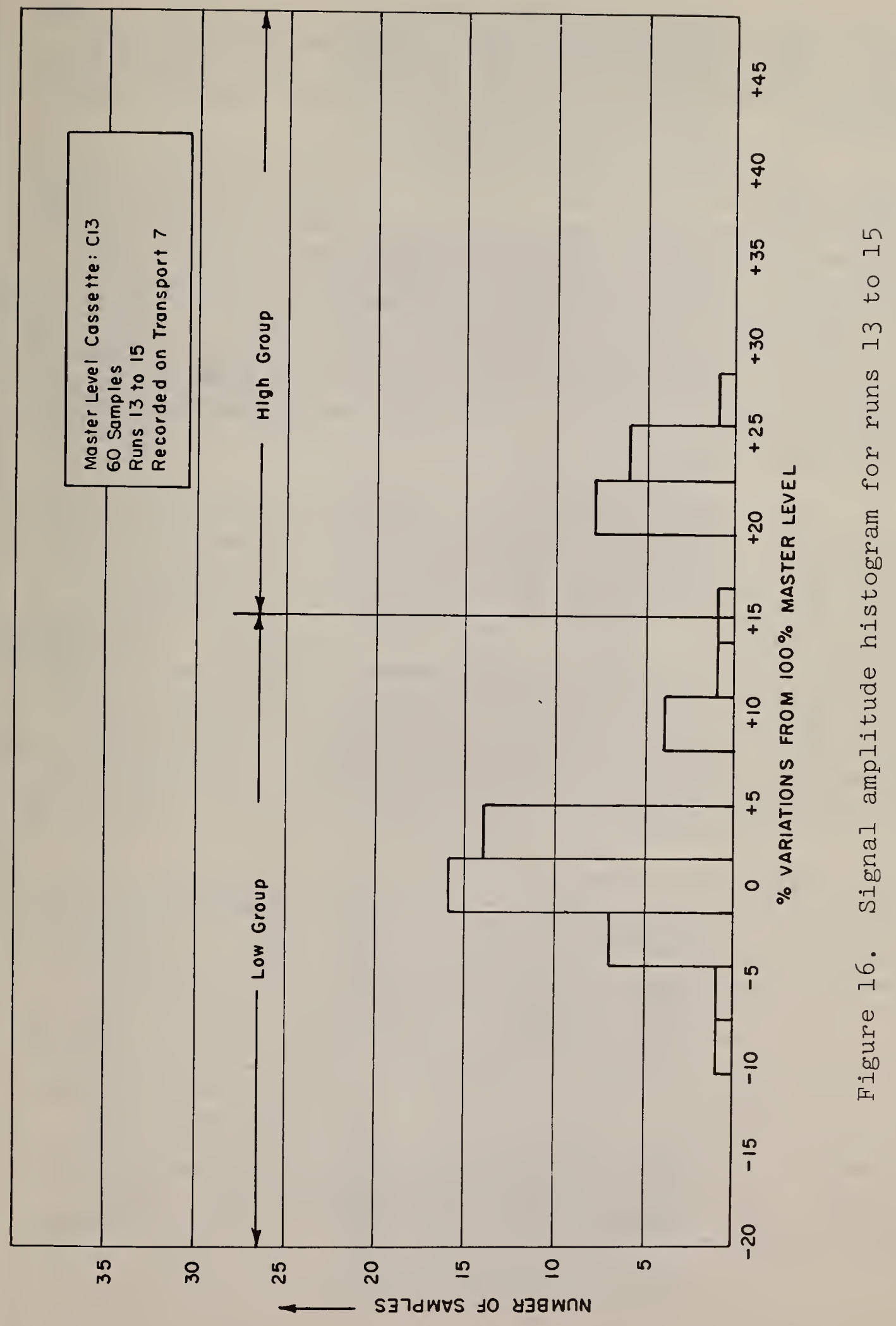


Note that the histograms were drawn on the basis of the complete data derived during each specified group of runs and that the "low-high" division about the $115 \%$ signal level naturally appeared from the full set of data without prior separation.

(5) The data in Tables $4 \mathrm{a}$ and $4 \mathrm{~b}$ were extracted from 6 track chart recordings such as that shown in figures 17 and 18. The data is the peak-to-peak signal amplitude shown on the bottom track (\#6). Figure 17 shows the 6 track chart recording derived from the $\mathrm{Cl} 3$ interim "master level" tape. Each track is set to the $100 \%$ chart level with the "Master Gain" adjustment that was discussed in section 4. Figure 18 shows the measurement chart derived from cassette B3 after the system was calibrated by $\mathrm{Cl3}$. Note that figure 17 shows the chart recorder set for a $2 \%$ variation per small division and figure 18 shows the chart recorder set for $1 \%$ variation per small division.

(6) The output voltages were measured directly at the read heads of some of the transports in response to the recorded interim "master level" cassette Cl3. There was no observed correlation among the absolute output voltage levels from different heads at different transport speeds in response to this as well as other recorded tapes. For example, for $\mathrm{Cl3}$ on transport \#4 the head output voltage was $1.87 \mathrm{mv}$ rms at $6.057 \mathrm{kHz}$; on transport \#7 the head output voltage was $3.55 \mathrm{mv} \mathrm{rms}$ at $10.31 \mathrm{kHz}$ and on transport \#l the head output voltage was $2.43 \mathrm{mv} \mathrm{rms}$ at $4.98 \mathrm{kHz}$. Therefore, it will be necessary to make all output measurements on a relative basis until such time that a "standard reference" read/write head is available.

(7) The data in tables $4 \mathrm{a}$ and $4 \mathrm{~b}$ were inspected to see if any of the test transports seemed to yield amplitude results which correlated with any of the others. Transport Nos. 1 and 4 seemed to be the most out of line, therefore, they were removed from further consideration as possible reference units: only the measurements made with transports $5,6,7$ and 8 were considered. It was found that for runs 1 through 6 that the maximum variation in relative amplitude for a tape which was run on these 4 transports was less than 10\% from transport to transport after each had been first calibrated to the $100 \%$ level by C13. For runs $7-12$ with the exceptions of tapes F8, F9 and F15 the maximum variation in relative amplitude was also approximately $10 \%$. Since transports 1 and 4 were used in runs 13-15 no maximum variation was computed. 

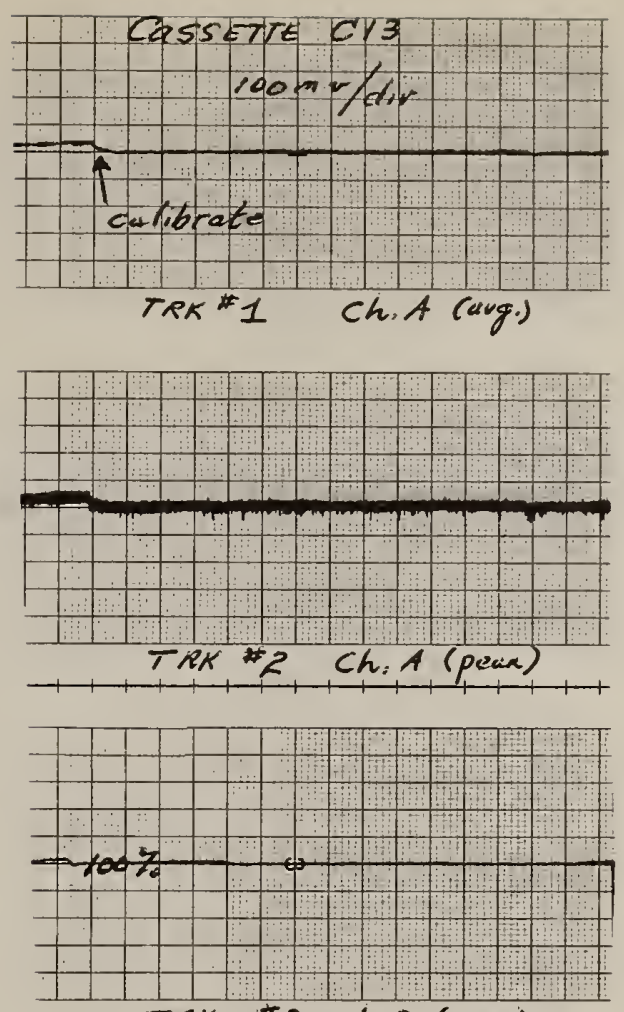

TRK $3 \operatorname{chB}$ (Avg.)

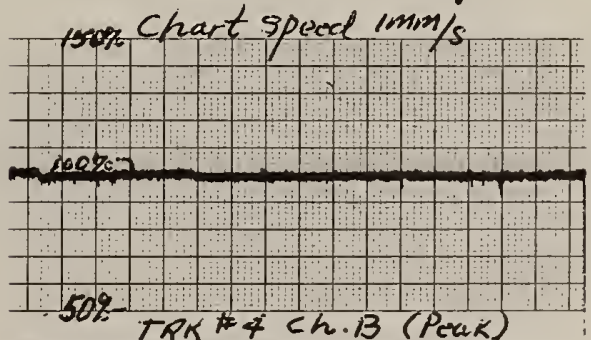

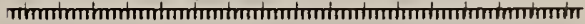
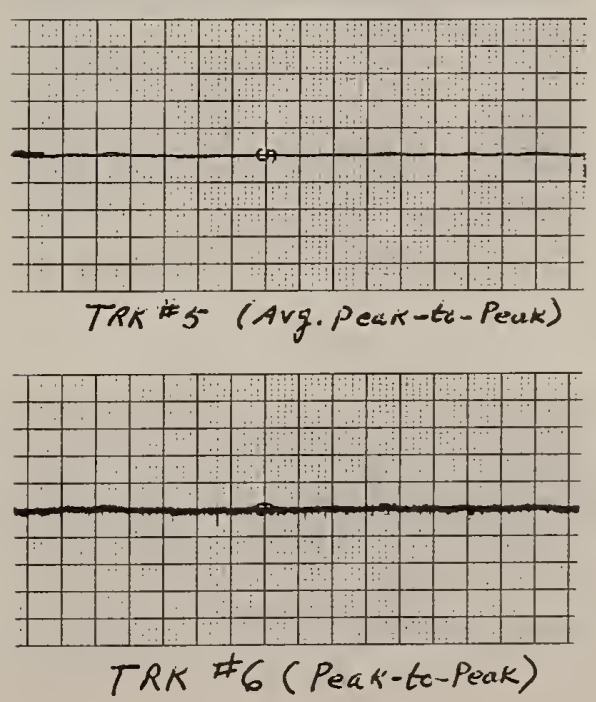

Figure 17. Six track chart recorder output curves 


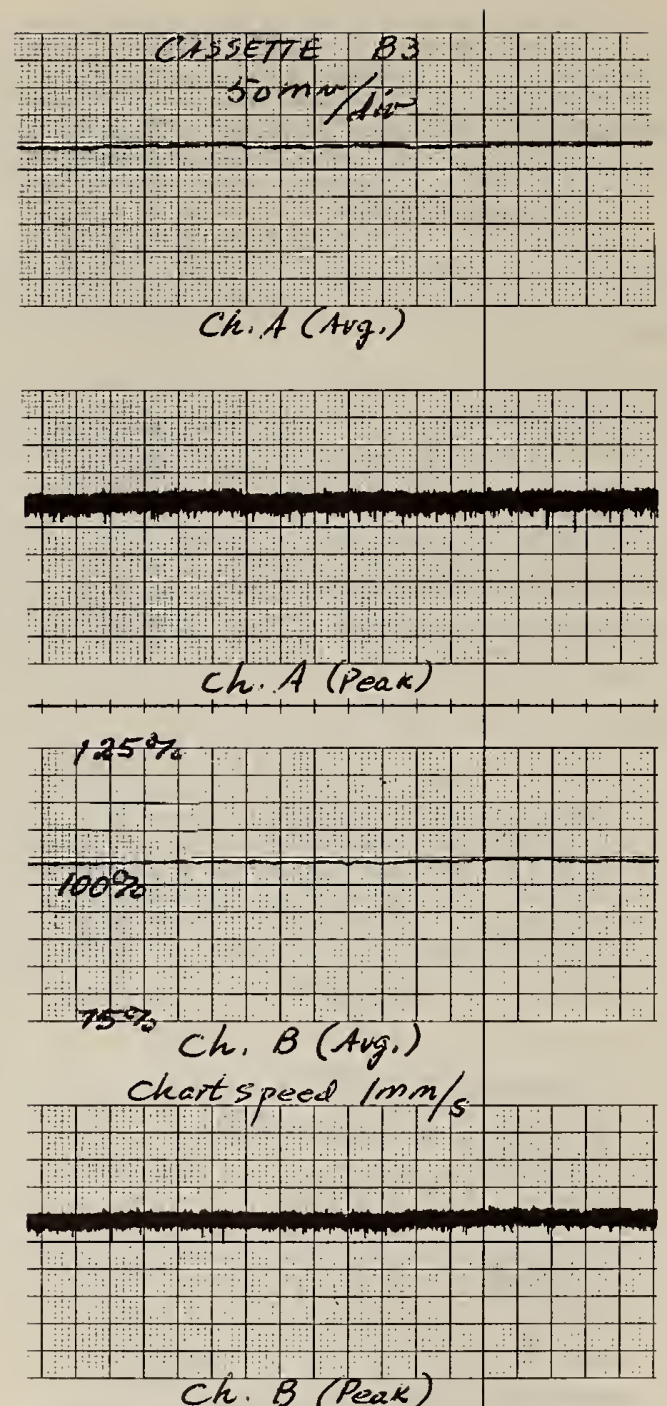

m
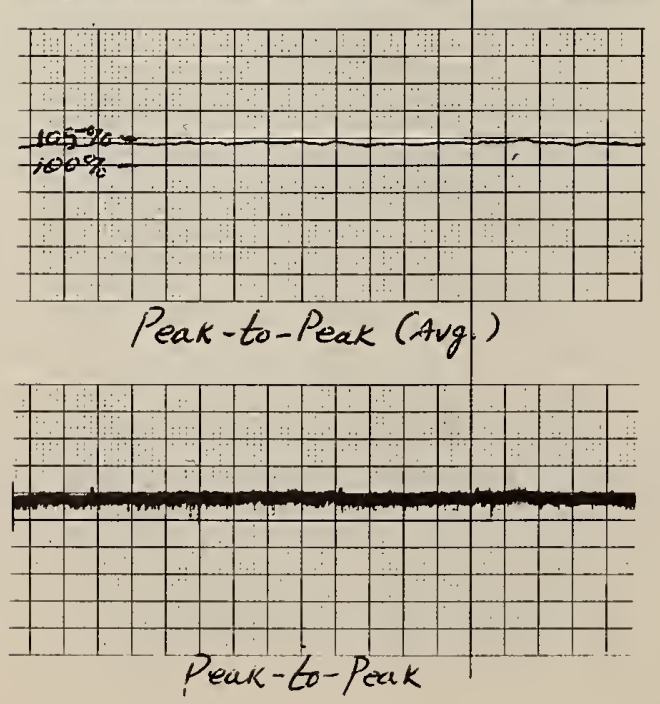

Figure 18. Six track chart recorder output curves 

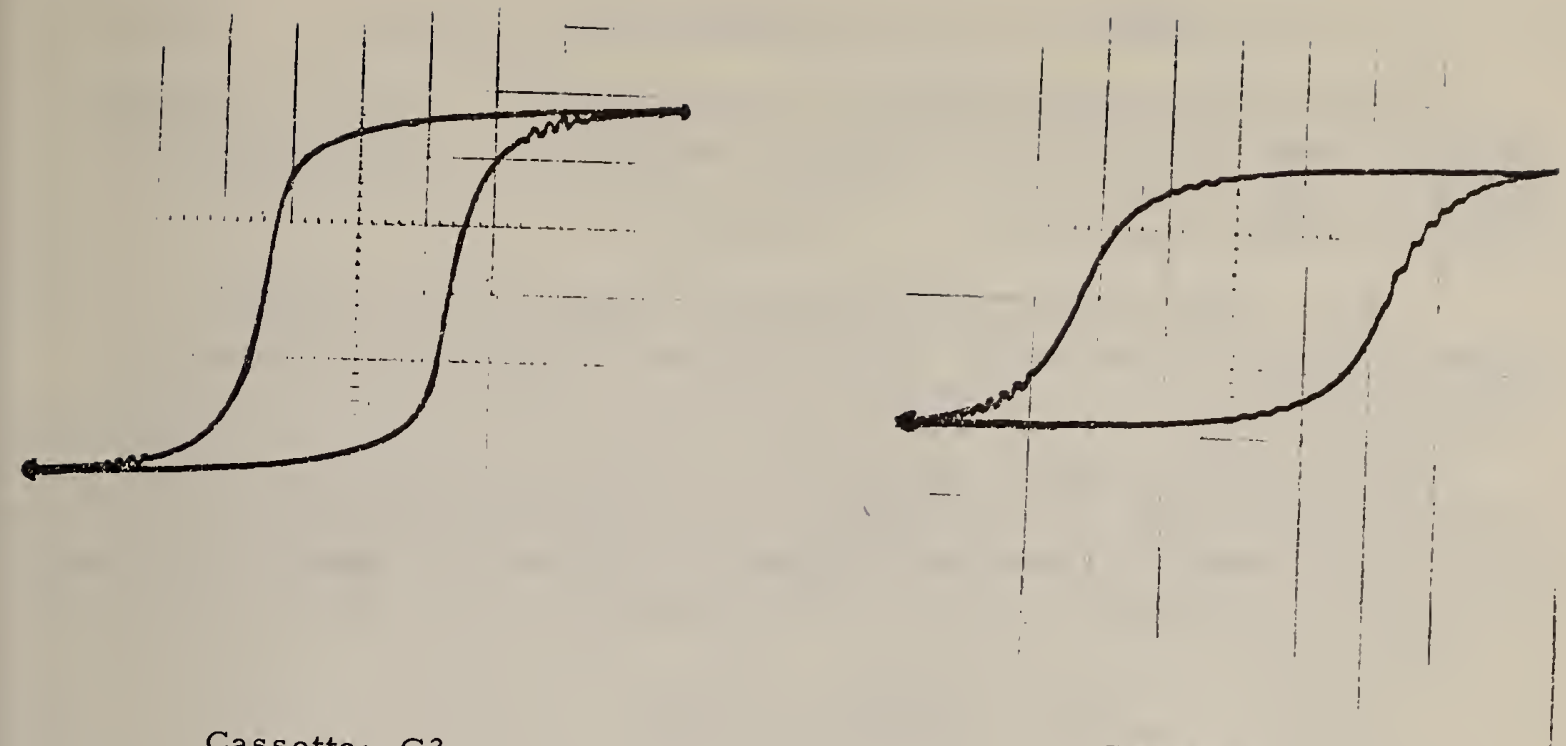

Cassette: G3

Cassette: Fl

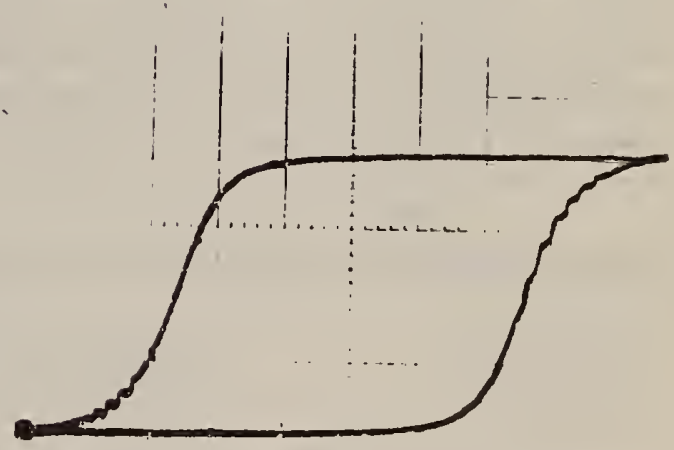

Cassette: $\mathrm{Cl} 3$

Cassette: C9

Horizontal Scale 16,000 A/m per division 200 Oe. per division

Vertical Scale $0.25\left(10^{-8}\right) \mathrm{Wb}$ per div.

$0.125 \mathrm{mx}$ per division

Figure 19. $\phi-\mathrm{H}$ Curves for Cassette Tapes

Figure 19. $\phi=\mathrm{H}$ loops for four cassettes 
(8) Additional Observations:

(a) Some cassettes had difficulty in running properly on some transports; however, cassettes which were produced by the manufacturer of the transport invariably ran well on that transport.

(b) Some cassettes which produced clean smooth chart traces on one pass would become highly erratic on an ensuing pass.

(c) The signal amplitude on the tapes would become stable by the 4 th or 5th pass: the signal amplitude from the lst to the 5th pass was found to decrease by approximately $5 \%$ on the average for the test cassettes.

\section{COMPONENT LIST}

The mention of specific equipments or components in any portion of publication is not to be construed as an endorsement of these items by NBS to the exclusion of other equivalent devices. There is considerable latitude in the choice of semi-conductor components, potentiometers, recording, reproducing and measuring devices. The following is a tabulation of some of the devices that are used in the NBS cassette measurement system:

Transistors $\mathrm{T}$ (Numbers in Figures)

Type

2N3646

$2 N 3638$

$2 N 916$

$7-10,27,28$
$6,11,12,13$
$1-3$

2N3821

$2 \mathrm{~N} 4222 \mathrm{~A}$
145
NPN Switching

PNP Switching

NPN High Frequency

Amplifier

NPN High Speed Switch

N-Channel FET
Diodes

1 1N276

1 N916
$\underline{D \text { (Numbers in Figures) }}$

$$
2, \frac{1}{3}, 4
$$

Type

Ge Switch

Si Switch
Amplifiers

PP $45 \mathrm{U}$
(Numbers in Figures)

$O A-1-$ to 10
Type

Operational Amplifier

(Solid State) 


\section{$\mu \mathrm{A} 710 \mathrm{C}$ \\ IC-1 \\ Differential Comparator}

\section{APPENDIX}

\subsection{Digital Cassette Standardization Progress}

Most of the effort in standardization work to date for the Philip's type of cassette has been carried out in Europe. Since the cassette was initially designed for audio applications, the first standards appeared in the IEC TC60 Audio Group. Document 94 from this group detailed, among other items, the physical specifications of the cassette. This was followed by Addition 1 which relaxed many of the tolerances of the original document. Around December 1969 ECMA began work on a digital cassette standard when it became apparent that manufacturers were going in many different directions and requested guidelines in the design of transports and choice of recording methods. With Addition 1 as the basis, ECMA produced a draft proposal which was accepted with minor modifications by ISO TC97/SC4/WGI as a First

Draft Proposal. The U.S. ANSI Task Group X3BI has had three meetings devoted toward the development of an ANSI digital cassette standard and is basing their work on the ECMA document. In the meantime, proposals for a $1 / 4$ inch digital tape cassette standard have been submitted in the U.S. and in Europe. None of the $1 / 4$ inch digital tape cassettes have been made available as yet for evaluation.

\subsection{Tape and Leader Dimensions}

The following specifications for the tape and leader have been taken from the most recent ECMA document on the compact cassette:

Tape Width:

3.81 to $-0.05 \mathrm{~mm}(0.150$ to -0.002 in)

Total Tape Thickness: $19 \mu \mathrm{m}(750 \mu$ in) maximum

Coating Thickness:

Tape Length:

$5 \pm 1 \mu \mathrm{m}(200 \pm 40 \mu$ in $)$

$86+4 m(282+13 \mathrm{ft})$

Leader Thickness:

$38 \mu \mathrm{m}(1500 \mu$ in) maximum 
Leader Length:

$500 \pm 50 \mathrm{~mm}(20 \pm 2$ in $)$

Measured from the cassette face to beginning of the magnetic tape (measured perpendicular to the cassette face).

BOT/EOT Markers

Shall be circular holes having a diameter of $0.6+0.05 \mathrm{~mm}(0.0237$ $+0.002 \mathrm{in})$. The distance of the marker centers from the physical beginning and of the magnetic tape (for BOT and EOT respectively) shall be $450 \pm 30 \mathrm{~mm}(17.7 \pm 1.2 \mathrm{in})$.

With respect to read signal output amplitude, manufacturers of cassettes appear to have separated into two groups whose signal output differs by about 30\%. (This was observed in the NBS laboratory as described in section 5). The lower signal output tapes are usually produced by the $1 / 2$ inch computer tape manufacturers who would like to keep the outputs of the cassette and computer tapes similar.

Although a digital cassette standard is well under way in the U.S.A. at the present time, quite a bit of work still remains before digital cassettes will be interchangeable both from a mechanical and information point of view. The quality of digital cassettes has improved to where drop-out free certified cassettes are now available. Due to the lack of a standard, however, there are quite a variety of recording techniques, control systems, track configurations, BOT/ EOT sensing techniques, etc., now available and most of these differences will have to be resolved if information interchange between different systems is to be achieved. ANSI$\mathrm{X} 3 \mathrm{~B} 1$ recognized that digital cassettes would be subjected to a wide variety of applications and included consideration of the applications in their program of work on cassettes. 


\section{REFERENCES}

[1] Geller, S.B., Mantek, P.A., Cleveland, N.G., Calibration of NBS Secondary Standard Magnetic Tape (Computer Amplitude Reference) SRM-3200 Using the Reference Tape Amplitude Measurement "Process A"; NBS Special Publication 260-18, November 1969.

[2] Geller, S.B., Calibration of NBS Secondary Standard Magnetic Tape (Computer Amplitude Reference) SRM-3200 Using the Reference Tape Amplitude Measurement "Process A" Model II; NBS Special Publication 260-29, June 1971. 


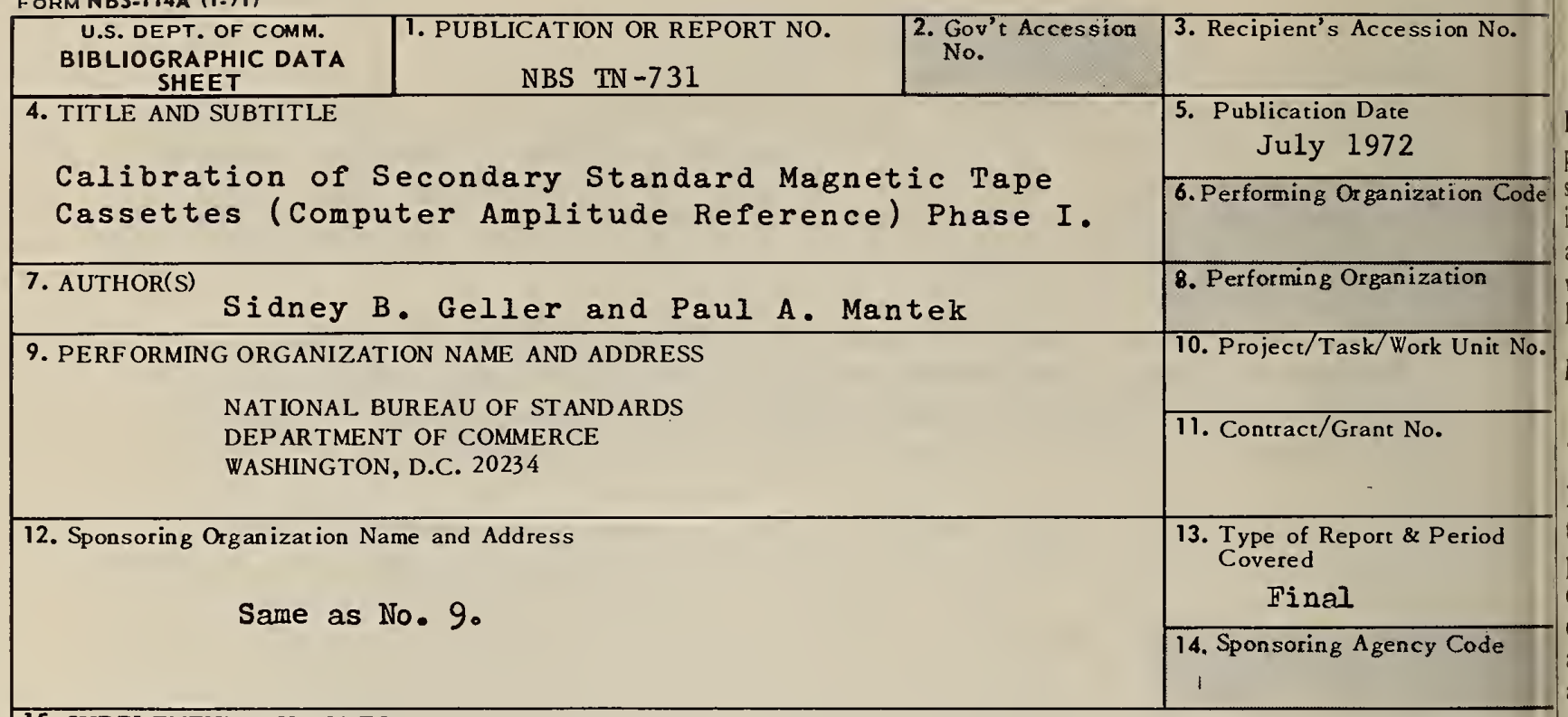

15. SUP PLEMENTARY NOTES

16. ABSTRACT (A 200-word or less factual summary of most significant information. If document includes a significant bibliography or literature survey, mention it here.)

This Technical Note discusses a method for developing and maintaining a reference system which will produce NBS Secondary Standard Magnetic Tape Cassettes (Computer Amplitude Reference). It describes both centerline tape search procedures and an interim signal amplitude measurement system for the reference magnetic tape cassette candidates The results of the initial experiments with cassette tapes and transports are given.

17. KEY WORDS (Alphabetical order, separated by semicolons)

Cassette tapes; cassette transport; computer amplitude reference; magnetic tape cassette; secondary standard; standard reference material 18. AVAILABILITY STATEMENT unrecorded references.

$\mathbf{X}$ UNL IMIT ED.

FOR OFFICIAL DISTRIBUTION. DO NOT RELEASE TO NTIS.

\begin{tabular}{|c|c|}
\hline $\begin{array}{l}\text { 19. SECURITY CL ASS } \\
\text { (THIS REPORT) } \\
\text { UNCL ASSIF IED }\end{array}$ & $\begin{array}{c}\text { 21. NO. OF PAGI } \\
60\end{array}$ \\
\hline $\begin{array}{l}\text { 20. SECURITY CLASS } \\
\text { (THIS PAGE) } \\
\text { UNCLASSIFIED }\end{array}$ & $\begin{array}{l}\text { 22. Price } \\
60 \text { cents }\end{array}$ \\
\hline
\end{tabular}


PERIODICALS

JOURNAL OF RESEARCH reports National Bureau of Standards research and development in physics, mathematics, and chemistry. Comprehensive scientific papers give complete details of the work, including laboratory data, experimental procedures, and theoretical and mathematical analyses. Illustrated with photographs, drawings, and charts. Includes listings of other NBS papers as issued.

Published in two sections, available separately:

\section{- Physics and Chemistry}

Papers of interest primarily to scientists working in these fields. This section covers a broad range of physical and chemical research, with major emphasis on standards of physical measurement, fundamental constants, and properties of matter. Issued six times a year. Annual subscription: Domestic, $\$ 9.50 ; \$ 2.25$ additional for foreign mailing.

\section{- Mathematical Sciences}

Studies and compilations designed mainly for the mathematician and theoretical physicist. Topics in mathematical statistics, theory of experiment design, numerical analysis, theoretical physics and chemistry, logical design and programming of computers and computer systems. Short numerical tables. Issued quarterly. Annual subscription: Domestic, \$5.00; $\$ 1.25$ additional for foreign mailing.

\section{TECHNICAL NEWS BULLETIN}

The best single source of information concerning the Bureau's measurement, research, developmental, cooperative, and publication activities, this monthly publication is designed for the industry-oriented individual whose daily work involves intimate contact with science and technology-for engineers, chemists, physicists, research managers, product-development managers, and company executives. Includes listing of all NBS papers as issued. Annual subscription: Domestic, $\$ 3.00 ; \$ 1.00$ additional for foreign mailing.

\section{Bibliographic Subscription Services}

The following current-awareness and literaturesurvey bibliographies are issued periodically by the Bureau: Cryogenic Data Center Current Awareness Service (weekly), Liquefied Natural Gas (quarterly), Superconducting Devices and Materials (quarterly), and Electromagnetic Metrology Current Awareness Service (monthly). Available only from NBS Boulder Laboratories. Ordering and cost information may be obtained from the Program Information Office, National Bureau of Standards, Boulder, Colorado 80302 .

\section{NONPERIODICALS}

Applied Mathematics Series. Mathematical tables, manuals, and studies.

Building Science Series. Research results, test methods, and performance criteria of building materials, components, systems, and structures.

Handbooks. Recommended codes of engineering and industrial practice (including safety codes) developed in cooperation with interested industries, professional organizations, and regulatory bodies.

Special Publications. Proceedings of NBS conferences, bibliographies, annual reports, wall charts, pamphlets, etc.

Monographs. Major contributions to the technical literature on various subjects related to the Bureau's scientific and technical activities.

National Standard Reference Data Series. NSRDS provides quantitative data on the physical and chemical properties of materials, compiled from the world's literature and critically evaluated.

Product Standards. Provide requirements for sizes, types, quality, and methods for testing various industrial products. These standards are developed cooperatively with interested Government and industry groups and provide the basis for common understanding of product characteristics for both buyers and sellers. Their use is voluntary.

Technical Notes. This series consists of communications and reports (covering both other-agency and NBS-sponsored work) of limited or transitory interest.

Federal Information Processing Standards Publications. This series is the official publication within the Federal Government for information on standards adopted and promulgated under the Public Law 89-306, and Bureau of the Budget Circular A-86 entitled, Standardization of Data Elements and Codes in Data Systems.

Consumer Information Series. Practical information, based on NBS research and experience, covering areas of interest to the consumer. Easily understandable language and illustrations provide useful background knowledge for shopping in today's technological marketplace.

\section{CATALOGS OF NBS PUBLICATIOHS}

NBS Special Publication 305, Publications of the NBS. 1966-1967. When ordering, include Catalog No. C13.10:305. Price $\$ 2.00 ; 50$ cents additional for foreign mailing.

NBS Special Publication 305, Supplement 1, Publications of the NBS, 1968-1969. When ordering, include Catalog No. C13.10:305/Suppl. 1. Price $\$ 4.50 ; \$ 1.25$ additional for foreign mailing.

NBS Special Publication 305, Supplement 2, Publications of the NBS, 1970. When ordering, include Catalog No. C13.10:305/Suppl. 2. Price $\$ 3.25 ; 85$ cents additional for foreign mailing. 
U.S. DEPARTMENT OF COMMERCE

National Bureau of Standards Washington. D.C. 20234

OFFICIAL BUSINESS

POSTAGE AND FEES PAID U.S. DEPARTMENT OF COMMERCE 215

Penalty for Private Use, $\$ 300$ 






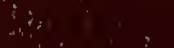

is

20

$i$

$i_{p} c$

\&

$=\left\{\begin{array}{c}2 \\ 5\end{array}\right.$

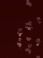

if

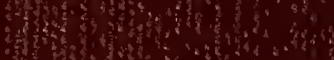

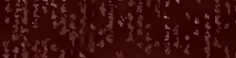

3ithy 